\title{
Gut Microbiota, Host Organism, and Diet Trialogue in Diabetes and Obesity
}

\author{
Veronica Lazar ${ }^{1,2 *}$, Lia-Mara Ditu ${ }^{1,2}$, Gratiela G. Pircalabioru ${ }^{2+}$, Ariana Picu ${ }^{1,3+}$, \\ Laura Petcu ${ }^{1,3+}$, Natalia Cucu ${ }^{4,5}$ and Mariana Carmen Chifiriuc ${ }^{1,2 \dagger}$
}

${ }^{1}$ Department of Microbiology and Immunology, Faculty of Biology, University of Bucharest, Bucharest, Romania, ${ }^{2}$ Earth, Environmental and Life Sciences Section, Research Institute of the University of Bucharest, University of Bucharest, Bucharest, Romania, ${ }^{3}$ National Institute for Diabetes, Nutrition and Metabolic Diseases Prof. Dr. N. Paulescu, Bucharest, Romania, ${ }^{4}$ Fundeni Clinical Institute, Bucharest, Romania, ${ }^{5}$ Department of Genetics, Faculty of Biology, University of Bucharest, Bucharest, Romania

\section{OPEN ACCESS}

Edited by:

Giovanna Suzzi,

University of Teramo, Italy

Reviewed by:

Anca Israil,

Cantacuzino National Institute of Research-Development for Microbiology and Immunology (CNIR), Romania

Teresa Zotta,

Italian National Research Counci

(CNR), Italy

${ }^{*}$ Correspondence:

Veronica Lazar

veronica.lazar2009@gmail.com

${ }^{\dagger}$ These authors have contributed equally to this work

Specialty section:

This article was submitted to Food Microbiology,

a section of the journal

Frontiers in Nutrition

Received: 19 December 2017

Accepted: 13 February 2019

Published: 13 March 2019

Citation:

Lazar V, Ditu L-M, Pircalabioru GG,

Picu A, Petcu L, Cucu N and Chifiriuc MC (2019) Gut Microbiota, Host Organism, and Diet Trialogue in

Diabetes and Obesity.

Front. Nutr. 6:21.

doi: 10.3389/fnut.2019.00021
The gastrointestinal tract with its microbiota is a complex, open, and integrated ecosystem with a high environmental exposure. It is widely accepted that the healthy gut microbiotais essential for host homeostasis and immunostasis, harboring an enormous number and variety of microorganisms and genes tailored by hundreds of exogenous and intrinsic host factors. The occurrence of dysbiosis may contribute to host vulnerability and progression to a large spectrum of infectious and non-communicable diseases, including diabetes and obesity, two metabolic disorders that are showing an endemic trend nowadays. There is an urgent need to develop efficient strategies to prevent and treat metabolic disorders such as diabetes and obesity which are often associated with serious complications. In this paper, we give an overview on the implications of gut microbiota in diabesity, with a focus on the triangle gut microbiota-diet-host metabolism and on the way to manipulate the gut microbial ecosystem toward achieving novel diagnosis and predictive biomarkers with the final goal of reestablishing the healthy metabolic condition. The current research data regarding the precision/personalized nutrition suggest that dietary interventions, including administration of pre-, pro-, and syn-biotics, as well as antibiotic treatment should be individually tailored to prevent chronic diseases based on the genetic background, food and beverage consumption, nutrient intake, microbiome, metabolome, and other omic profiles.

Keywords: microbiome, gut physiology, diet, diabetes, obesity, prebiotics, probiotics

\section{INTRODUCTION}

Human microbiota includes bacteria, fungi, archaea, protozoans, and viruses, which seem to be even more numerous compared to those contained in the human genome (1). The microorganisms inhabiting the organism achieve a perfect mutual synergy with its host, being often referred together as a "superorganism" or a host extra-organ. The gastrointestinal tract (GIT) contains at least $10^{14}$ bacteria, with the highest density achieved in the large intestine, while the number of genes (intestinal microbiome) is superior (150- to 500-fold) to human DNA (2). Thus, GIT microbiota could be practically considered the fourth organ of the digestive system or the "forgotten organ" living in the gut like in a bioreactor (3). Large-scale projects, such as the European Metagenomics of the Human Intestinal Tract (MetaHIT) (4) and the US Human Microbiome Project Consortium(5) 
report more than 2,000 species, classified into 12 different phyla, of which $93.5 \%$ belong to Proteobacteria, Firmicutes, Actinobacteria, and Bacteroidetes (6-8). Independently of birth place, sex, age, or body weight, there are three predominant "enterotypes," enriched in Bacteroides, Ruminococcus, and Prevotella (9). The GIT microbiota composition (diversity or the abundance of particular species) is shaped by hundreds of factors, including host genetics, mode of delivery (Figure 1), gender, age, height, weight, diet, immune system, gastrointestinal secretions blood levels of various molecules or red blood cell counts, stool consistency, sleep, medical history, ethno-geographical and socio-economic conditions, sanitary conditions, smoking, antibiotics and antibiotics-like substances, laxatives and less intuitive drugs (e.g., antihistamines, antidepressants, and metformin) (10-13). A deep sequencing study of the gut microbiomes revealed correlations between the microbiome and 126 exogenous and intrinsic host factors, including 12 diseases, 31 intrinsic factors, 19 drug groups, 60 dietary factors, and 4 smoking categories (10).

\section{ROLE OF GIT MICROBIOTA IN THE HOST ENERGY BALANCE}

GIT microbiota plays a significant role in human health and disease (1) (Figure 2). The microbiota is a major player in energy harvest and storage, as well as in a variety of metabolic functions, such as bile acids and choline transformation, fermenting and absorbing undigested carbohydrates or providing vitamins and amino acids for the host (14).

Recent studies show that the microbiota may impact weightgain and adiposity via several inter-connected pathways, such as energy harvest and production of microbial metabolites, through effects on inflammatory responses and on the gut-brain axis.

One of the most important metabolic activity of GIT microbiota is the production of non-gaseous SCFAs (acetate, propionate, and butyrate), through fermentation of microbiotaaccessible, complex carbohydrates (MAC) (e.g., oligosaccharides, resistant starch, and plant cell wall materials) (15-17). The predominant commensal bacteria that produce SCFAs are represented by Akkermansia muciniphilia, Prevotella spp., Ruminococus spp., Coprococcus sp., Faecalibacterium prausnitzii, Eubacterium rectale, and Roseburia spp. (18). Absorbable SCFAs are important modulators of gut health and immune function (19), intestinal hormone production, and lipogenesis (20). SCFAs can interact with the host through many pathways. SCFAs signal through G-protein-coupled receptors such as G-protein coupled receptor GPR41 and GPR43 which affect crucial processes (e.g., inflammation, expression of tight junction proteins, and enteroendocrine regulation) and have a crucial role in maintaining an acid $\mathrm{pH}$ favoring the proliferation of certain bacterial species $(16,21,22)$. Propionate, butyrate, and acetate trigger the local release of peptide YY (PYY) and of glucagon-like neuropeptide-1 (GLP-1) from enteroendocrine L cells regulating digestion and alter the liver function by modulating lipid metabolism with an indirect effect on the storage of fatty acids in the liver. Butyrate in particular is an energy substrate for colonocytes, releasing 1,000 kcal/day. Due to the trophic role on the intestinal epithelium and by promoting GLP-2 release and increasing mucus secretion, butyrate decreases the permeability of the intestinal barrier and is protective against colitis and colorectal cancers. SCFAs pathways were shown to be elevated in obesity metagenomic studies, and SCFAs levels were higher in overweight or obese people and animal models. Propionate is a substrate for gluconeogenesis, which signals through the central nervous system and protects the host from diet-induced obesity and glucose intolerance. Increased levels of propionate were associated with the microbiota following gastric bypass, which granted protection from diet-induced obesity upon transfer to germ-free recipient mice $(2,18)$.

Gut microbial metabolism of choline (a water-soluble nutrient essential for human life, found in eggs, seafood, beef, turkey and chicken, tuna, salmon, code and sardines, broccoli, cauliflower, cabbage, spinach, green peas, mushrooms, tomatoes etc.) leads to accumulation of trimethylamine (TMA), which is converted in the host liver to trimethylamine- $N$-oxide (TMAO) by flavinmonooxigenenase 3 (FMO3) (2). Circulating levels of TMAO were linked to an increased risk of cardiovascular diseases mortality and type 2 diabetes (T2DM) (23). Regulation of TMAproducing microbial species or their activity in the intestinal microbiota could aid to find novel means for preventing or treating atherosclerosis and choline deficiency-associated diseases. Resveratrol reduces TMAO levels through downregulation of the enterohepatic farnesoid $\mathrm{X}$ receptor-fibroblast growth factor (FXR) axis, indicating that the gut microbiota is a potent target for personalized medicine interventions in diminishing metabolic disease development risk (24, 25). Another TMAO precursor, betaine is also widely distributed in animals (seafood), plants (spinach, wheat germ, bran) and microorganisms, mainly acting as an osmolyte (protecting cells and proteins from environmental stress) and methyl donor (transmethylation). Insufficient dietary levels of methyl groups results in hypomethylation in several metabolic pathways such as the hepatic fat metabolism, leading to steatosis and plasma dyslipidemia. Betaine was reported to protect internal organs, improving vascular risk factors, and enhancing performance, these beneficial effects justifying the efforts for the development of databases concerning betaine content in food (26).

Secondary bile acids are generated from cholesterol by microbiota of the lower small intestine and colon. By binding to distinct receptors, such as G-protein-coupled bile acid receptor 1 (TGR5) and the bile acid receptor FXR, secondary bile acids serve as signaling molecules. The ability to metabolize the naturally occurring FXR antagonist tauro- $\beta$-muricholic acid is an essential process toward obesity, steatosis, as well as impaired tolerance to glucose and insulin. Bariatric surgery is associated with changes in the metabolism of bile acids and in the microbiota composition. Germ-free mice that received a fecal transplant from people that had Roux-en-Y gastric bypass 10 years before, gained less fat compared to mice that were colonized by microbiota from obese people (2).

Importantly, the microbiota regulates tissue-level immune maturation via the microbial metabolism of tryptophan. Specifically, commensal Lactobacilli use tryptophan as an energy 


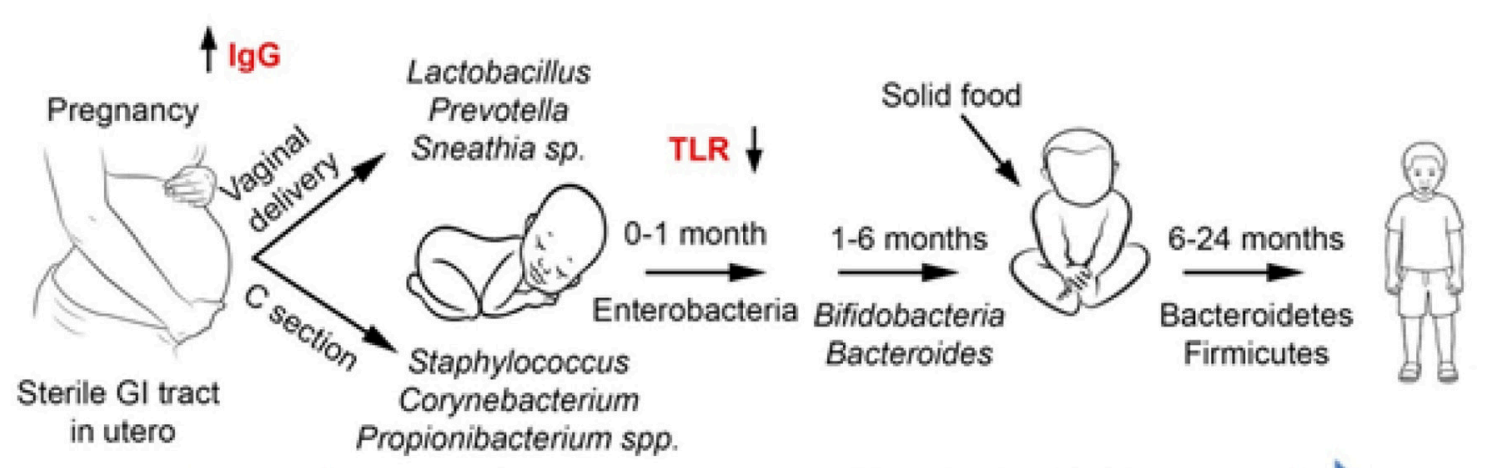

Increasing diversity

FIGURE 1 | Development of gut microbiota. During the first years of life, the microbiota is largely influenced by external factors, such as delivery mode and type of feeding (breast or artificial formula feeding). Subsequently, the intake of solid food as well as the gradual maturation of the immune system modulates the gut microbiota. By the age of 2-3 years old, the microbiota resembles that of an adult with Bacteroidetes and Firmicutes as the main phyla.

source to generate ligands of the aryl hydrocarbon receptor (AhR), a transcription factor involved in the organogenesis of intestinal lymphoid follicles (ILFs). AhR impacts IL-22 production and thus affect the secretion of anti-microbial peptides (lipocalin-2, S100A8, and S100A9) (27).

Other microbial metabolites whose functions in the host physiology and pathophysiology are still not yet elucidated include: indole propionic acid, associated with an improved epithelial barrier in the gut; ethylphenyl sulfate, correlated with the exacerbation of autistic behavior in a mouse model; indoxylsulfate and $p$-cresyl sulfate, both linked with poor cardiovascular outcomes in patients with uremia (2).

The brain signals to the gut through efferent vagal signaling and neuroendocrine pathways. The communication pathway with the microbiota is direct when neurotransmitters (5hydroxytryptamine [5-HT], $\gamma$-aminobutyric acid [GABA], catecholamines) are sensed by the microorganisms, or indirect, via effects on the intestinal niche. The intestinal microenvironment can be modified by vagal efferent nerves involved in intestinal physiology (i.e., mucus secretion), mucosal immune responses, gut motility, intestinal barrier function, all of which impact microbiome composition and function (28).

The intestine signals to the brain via blood-borne substances or through afferent vagal and spinal nerves. Metabolites released by the microbiota can act as signaling molecules that regulate hormone \{peptide YY [PYY], glucagon-like peptide-1 [GLP1]\} secretion from intestinal enteroendocrine cells. GLP-1 and PYY have receptors expressed in brain regions involved in the regulation of host energy balance (29).

\section{Host (Epi)genetics-Git Microbiota-Diet Metabolic Interplay}

The gut microbiota of traditional rural populations in various parts of the world that have been separated for thousands of years on different continents showed increased bacterial diversity and presence of microbial taxa, lacking from the Western populations, suggesting that modern lifestyles, medical practices and processed foods in the industrialized world lead to an overall decline in gut microbiome biodiversity and loss of specific phylogenetic groups.

The microbiota contributes to the bioavailability, transformation, absorption, and/or excretion of several chemical elements including selenium, zinc, cobalt, and iodine all of which are co-factors for various enzymes involved in epigenetic processes (30).

Several studies proved an interplay between host genetics and diet in regulating the microbiome composition. Modifications in adiposity and metabolic response of low-calorie, weightloss diets could be significantly altered by different genetic variants, especially those linked to T2DM, obesity, food preference and metabolism (23). A genome-wide significant variant in LCT region (lactase gene) modulating Bifidobacterium sp. abundance in the intestinal microbiome, associated with dairy intake was recently identified. A study in the elderly Mediterranean population revealed an association of the LCT variant and obesity, significantly regulated by dairy lactose and milk intake (23). Therefore, diet could alter the composition and/or abundance of the intestinal microbiota, as well as the microbial metabolome $(31,32)$. For instance, studies in Japanese populations have reported that after consumption of seaweeds, the genes encoding enzymes involved in metabolizing marine red algae were transferred from the marine-associated bacteria to certain bacteria in the intestinal microbiome (20). In fact, the microbiome has a huge role in extending our own metabolism for constituting the hologenome, defined as the sum of the host and its microbiota genetic information, representing the result of their longtime coevolution, finally achieving the host metabolic diversity $(33,34)$. Many bacterial enzymes, such as beta-glucosidase, beta-glucuronidase, nitroreductase, azoreductase, 7-alpha-dehydroxilase, cholesterol-dehydrogenase are inducible enzymes whose colon concentration is strongly influenced by the diet. Interestingly, omnivorous subjects had 


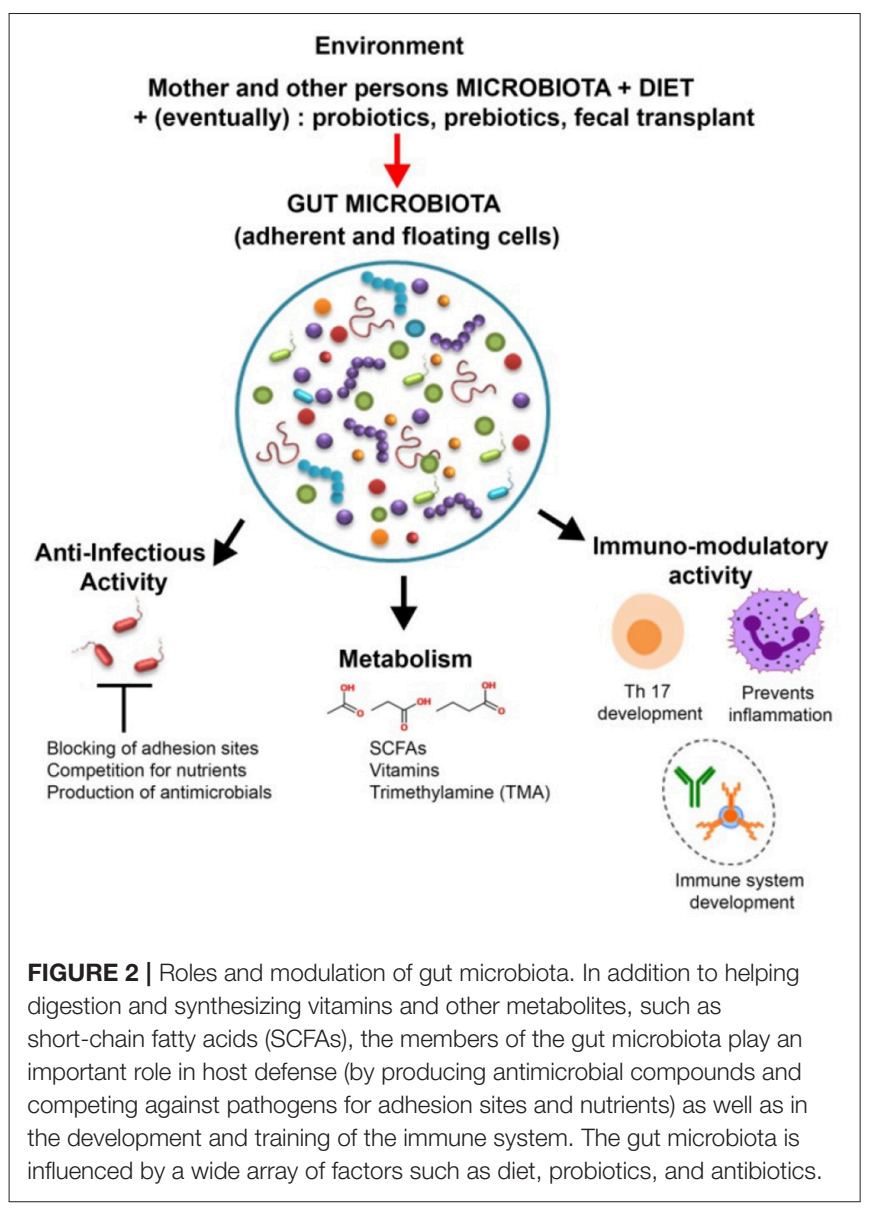

enhanced TMAO levels compared to vegans or vegetarians after ingesting L-carnitine, via an intestinal microbiota-dependent mechanism (20). There are reports of a gene-diet interaction in regulating Bifidobacterium sp. and other genera abundance, hence demonstrating the importance of host-microbiome interplay $(17,31)$.

Microbiota can promote epigenetic modification: the host responds to environmental factors through the alterations of DNA methylation and histone modifications. DNA methylation affects gene expression by regulating accessibility of the transcriptional machinery, transcription factors, and histone modifiers and to chromatin. DNA methyltransferases (DNMTs) can add a methyl group from the donor S-adenosylmethionine (SAM) to the carbon-5 position of the cytosine $(5 \mathrm{mC})$, whereas the ten-eleven translocation enzyme (TET) dioxygenase family oxidizes $5 \mathrm{mC}$ to hydroxymethylcytosine $(5 \mathrm{hmC})$. Bacteria such as Bifidobacterium and Lactobacillus produce folate which supports the generation of SAM (35). Dietary methionine modulates the composition of the host microbiota as well as bacterial metabolism to release substrates for SAM synthesis. The mechanisms involved in microbiota-dependent modification of histones are still poorly understood. Acetylation of histones exposes target sites in nucleosomal DNA for transcription factors whereas deacetylation triggered by histone deacetylase (HDAC) removes acetyl groups from histone tails, hence leading to a reduction in transcriptional accessibility. Butyrate, produced by various commensal bacteria (Faecalibacterium, Coprococcus, Roseburia, Eubacterium, etc.) from dietary fiber has emerged as a HDAC inhibitor, with anti-inflammatory activity by suppressing STAT1 and NF-kB activation (36).

Several infectious agents (human papilloma virus, hepatitis viruses B and C, Epstein-Barr virus, polyomaviruses, Chlamydia pneumoniae, Campylobacter rectus, Streptococcus bovis, Helicobacter pylori) and members of the gut microbiota are epigenetic factors implicated in the metabolic syndrome pathogenesis. An example of an indirect action of microbial low molecular weight (LMW) molecules on chromatin remodeling, is the deficiency of some substrates (betaine, methionine, choline) and/or cofactors (vitamins B12, B2, B6, folate) generated by the microbiota. Indigenous intestinal bacteria may affect the bioavailability of dietary methyl groups and cause the hypomethylation of several epigenomic-associated pathways. This alteration may hinder DNA methylation leading to decreased SAM content, elevated plasma homocysteine concentrations, and elevated risk of various hepatica and vascular diseases, as well as malignancy. LMW molecules including SCFAs, sulforaphane cysteine/sulforaphane N-acetylcysteine and allylmercaptan/diallyldisulfide produced during the microbial metabolism of cruciferous vegetables or garlic could interfere with the activity of other enzymes responsible for epigenetic modifications, such as deacetylases, acetyltransferases, phosphotranferases, nucleases, serine-threonine protein kinases, etc. Also, gut microbiota is the main donor of acetyl groups for the formation of acetyl-CoA that is involved in epigenomic acetylation reactions. Bacteria and eukaryotes biosynthesise coenzyme A (CoA) from pantothenate, cysteine and $\beta$-alanine, all of which are found in most foods in small amounts and also produced by the gut microbiota. Deficiencies in these nutrients impair the synthesis of $\mathrm{NADH}$, acetyl-CoA, and NAD, leading to disorders of the epigenomic acetylation machine involved in chromatin remodeling and post-translational protein modifications (30).

\section{Interplay of Factors Involved in Diabetes, Obesity, Oxidative Stress, And Inflammation}

According to WHO report (37), the number of people with diabetes was four times higher in 2014 than in 1980, the majority living in developed countries and the WHO's prediction for 2035 is that diabetes will become the seventh cause of death worldwide, its prevalence increasing in low-income countries (37). The International Diabetes Federation (IDF) currently estimates that so far 415 million people worldwide have been diagnosed with T2DM and anticipate an increase up to 640 million by the year $2040(38,39)$. Diabesity describes the association between T2DM and obesity, both being a worldwide health problem, due to their extremely high prevalence and serious complications, particularly cardiovascular, respectively micro and macroangiopathy associated with accelerated vascular aging leading to atherosclerosis and microvascular dysfunction. According to the statistical data published by World Health 
Organization (WHO), in 2030 about a fifth of the world's adult population will suffer from metabolic syndrome and almost 23.6 million people will die from cardiovascular disorders (32). The interactions between genetic and environmental factors such as over-nutrition and a sedentary lifestyle lead to the development of these polygenic diet-related diseases with epidemic proportions $(40,41)$. Insulin resistance is also associated with an increased flux of free fatty acids (FFA) contributing to diabetic dyslipidemia, one of the major risk factors for cardiovascular disease in diabetes patients. Thus, an impaired glucose and lipid metabolism is the hallmark of metabolic syndrome, defined by central (abdominal) obesity and the presence of two to four of the following factorsreduced high density lipoprotein (HDL) cholesterol, high blood pressure, elevated triglycerides, higher resting metabolic rates (42) and increased fasting blood glucose. Obesity adds to the genetic susceptibility, insulin resistance due to FFA and tumor necrosis factor $-\alpha$ (TNF- $\alpha$ ), an inhibitor of insulin receptor kinase activity, leptin-regulating hormone appetite and adiponectin $(43,44)$. The inflammatory theory of the diabetogenic process and the chronic complications installed in the context of insulin resistance and obesity is intensely debated, but not fully elucidated $(45,46)$. Obesity is a major risk factor for T2DM leading to destruction of insulin receptors causing insulin resistance. Obesity is characterized by hypertrophy and hyperplasia of the white adipose tissue and the transformation of "silent" adipocytes into aggressive adipocytes, capable of autonomous inflammation, apoptosis and increased secretion of proinflammatory adipokines (47). The white adipose tissue is producing more than 100 various signal molecules, such as hormones (adiponectin, leptin, resistin, visfatin), chemokines, such as monocyte chemoattractant protein-1 (MCP-1) and proinflammatory cytokines, including TNF- $\alpha$ and interleukin6 (IL-6) all culminating in a "low grade inflammation" with multiple effects on the endothelial cells (48). There are at least three intracellular signaling pathways linking obesity to inflammation: the proinflammatory kinases pathway, the suppressors of cytokine signaling proteins (SOCS) pathway and the oxidative stress (49). Adiponectin is secreted only by the white adipose tissue (48) and its serum concentration is paradoxically inversely proportional to the body mass index (BMI); numerous studies have clearly revealed its antiinflammatory and anti-apoptotic roles, as well as its insulin sensitivity (48). In obese individuals the connection between serum leptinemia and the percentage of body adiposity is best observed (47). Leptin has a direct inhibitory effect on both basal as well as glucose-induced insulin level, through different mechanisms, also modulating the expression of secreted and membrane-associated mucins in colonic epithelial cells, targeting protein kinase C (PKC), phosphatidylinositol-3kinase (PI3K) and mitogen-activated protein kinases (MAPK) pathways (50). Complexity is also evident in the process of transporting glucose into adipocytes; 8 out of the 14 members of the glucose transporters (GLUT) are expressed in adipocytes. The SOCS1, SOCS3, SOCS6 proteins are involved in increasing insulin resistance by inhibiting insulin sensitivity (51).
The overlapping of metabolic and immune processes can become detrimental under metabolic stress conditions, such as the immunosuppression characteristic of malnourished individuals (52). The adipose tissue releases cytokines that cause up regulation of nicotine-amide-adenine diphosphate oxidase enzyme (NADPH), nitric oxide synthase (NOS), and myeloperoxidase (MPO) from macrophages and adipocytes, favoring the inflammatory processes. Chronic hyperglycemia leads to an activation of glucose self-oxidation processes, formation of highly reactive hydroxyl free radicals and decrease of antioxidant capacity and glutathione regeneration (53). The non-enzymatic glycation processes render proteins more susceptible to oxidative stress processes. Hyperglycemia also stimulates the hexosamine pathway, inducing the formation of fructose-6-phosphate, a protein glycosylation substrate with proteoglycan production, but also changes in gene expression for plasminogen activator inhibitor (PAI) and tumor growth factor $-\beta$ (TGF- $\beta$ ). Glycation of lipoproteins leads to decreased low density lipoprotein (LDL)-cholesterol catabolism and accelerated catabolism of high density lipoprotein (HDL)-cholesterol, favoring atherosclerosis and micro-/macro-vascular T2DM complications. Increased oxidative stress due to the persistence in circulation of triglyceride-rich lipoproteins along with chronic hyperglycemia is closely related to changes in monocyte and macrophage function (54). Catabolism of glycated proteins leads to the generation of advanced glycation end products (AGEs), stimulating IL-1 synthesis with fibroblast proliferation and endothelial damage. Among the consequences of excess reactive oxygen species (ROS) production is the complex process of lipid peroxidation, the resulting products being extremely unstable. Polyunsaturated fatty acids oxidation cascade is highly activated by free radical molecules (55), leading to the activation of a proinflammatory type processes via the mRNAactivated p38MAPK, c-Jun N-terminal kinases (JNK), Janus kinase (JAK), NF-kB, TGF- $\beta$, which either directly inhibit insulin activity or lead to a synthesis of inflammatory mediators. The synthesized proinflammatory cytokines stimulate ROS synthesis and intensify oxidative stress (56). The oxidative stress and inflammation, especially when associated with obesity, coexist and mutually potentiate, leading finally to insulin resistance, beta-pancreatic cell dysfunction, and vascular complications of T2DM (Figure 3).

Several studies have associated oxidative stress with dysbiosis. The intestinal tract has a radial oxygen gradient hence microbes residing on the colonic mucosa harbor elevated oxygen tolerance and catalase expression compared to luminal or stool-associated bacteria (58). In addition, inflammation usually promotes an oxidative state which enhance the enrichment of aerotolerant phyla such as Actinobacteria and Proteobacteria. Intestinal inflammation has also been shown to increase the production of terminal electron acceptors for facultative anaerobes such as Enterobacteriaceae further augmenting dysbiosis in the intestine $(59,60)$.

\section{Microbial Signatures in T2DM and Obesity}

The disruption of normal microbiota (generally referred to as dysbiosis) has been described to be involved in a large spectrum 


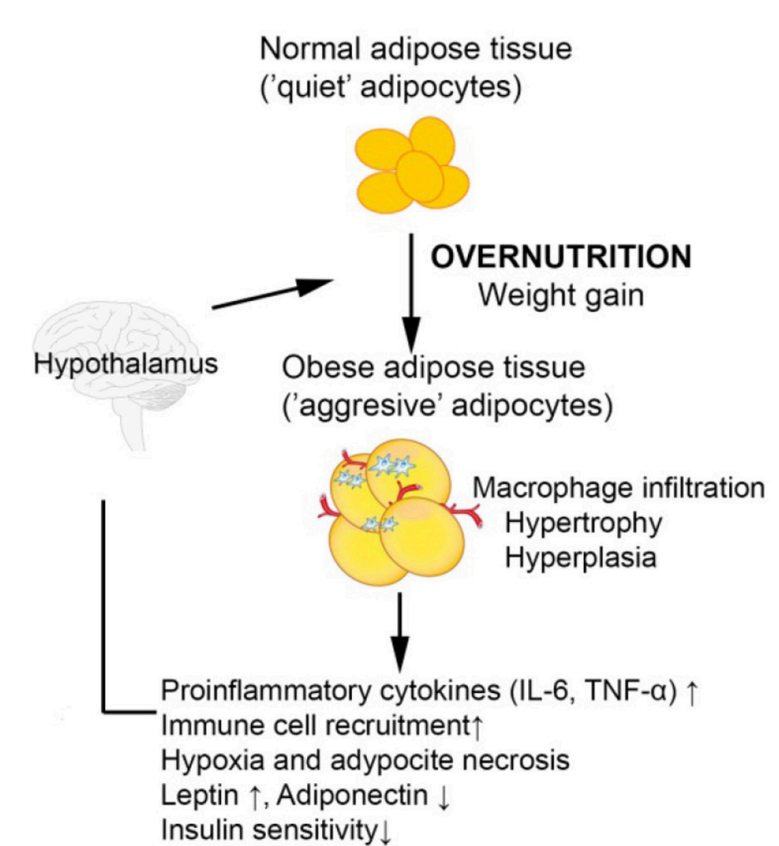

Normal adipose tissue

('quiet' adipocytes)

Insulin sensitivity $\downarrow$

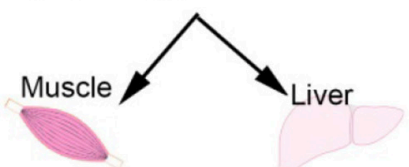

Glucose uptake $\downarrow$

Fatty acids oxidation $\downarrow$

Lipid accumulation

Inflammation

Insulin resistance

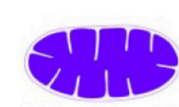

Mitochondria Metabolism

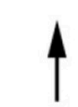

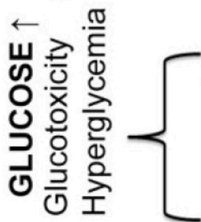

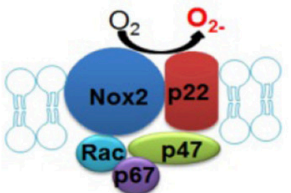

NOS

(Nitric oxide synthase)

\section{NADPH oxidase}

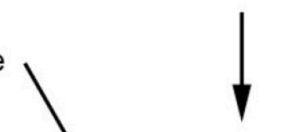

Autooxidation

Polyol pathway

Hexosamine pathway

Protein kinase $\mathrm{C}$

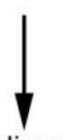

Signaling pathways

(p38 MAPK, NFkB,TGF- $\beta$ )

Lipid peroxidation

DNA damage

Protein damage

Insulin resistance

Dysfunction of pancreatic $\beta$ cells

Micro- and macrovascular

complications of T2DM

FIGURE 3 | Cellular mechanisms by which oxidative stress is involved in T2DM associated with obesity [adapted after (57)]. In obesity, the expansion of the adipose tissue promotes increased macrophage infiltration and inflammation with increased production of pro-inflammatory cytokines TNF $\alpha$ and IL-6. This is accompanied by an increased release of free fatty acids and an aberrant secretion of adiponectin and leptin. The resulting chronic hyperglycemia determines the activation of glucose self-oxidation processes that lead to the formation of highly reactive hydroxyl radicals which together with nitric oxide (NO) forms peroxinitrite, a very aggressive radical that causes oxidative damage to DNA, proteins, and lipids. The increased oxidative stress also activates signaling pathways such as p38 MAPK, NF-kB which are involved in insulin resistance and vascular complications of T2DM.

of diseases, including diabetes, obesity, and insulin resistance (61), through disturbing the energy balance (by increasing the metabolic rate; coordination of choline availability, affecting indirectly the liver storage of triglycerides; inhibition of fastinginduced adipose factor-FIAF expression which promotes triglyceride deposition in adipocytes; production of SCFAs which increase lipogenesis, inhibit fatty acids oxidation and trigger the intestinal absorption of monosaccharides by stimulating GLUT1 expression, modulation of YYP and GLP-1 hormones, modulation of intestinal motility and permeability, activation of Toll-like receptors, etc. (62-65).

It has been therefore suggested that the modulation of microbiota, either directly (by antimicrobials, diet, prebiotics and/or probiotics, stool transplant, microbial-derived signaling molecules or metabolites) or indirectly (e.g., immunotherapy) may contribute to the therapeutic management of these pathologies (66).
The impact of the intestinal microbiome on the pathophysiology of diabetes was revealed by several diabetes prone animals, specifically non-obese diabetic (NOD) mice and bio-breeding diabetes prone (BB-DP) rats and human studies. An initial study revealed that NOD mice with a chronic viral infection harbored a lower diabetes incidence (67). Mycobacterial infection followed by stimulation with bacterial antigens decreased the incidence of diabetes development in NOD mice, whereas a germ-free environment increases the risk of diabetes development (15). Nevertheless, recent studies showed that rather certain microbiota members (i.e., Bacillus cereus) were responsible for modulating the risk of diabetes development (68). A study by Brugman et al. (69), that used BB-DP rats and fluorescence in situ hybridization specific for 16S rRNA of Clostridium sp., Bacteroides sp. and Lactobacillus sp., revealed that rats developing diabetes were colonized by higher levels of Bacteroides sp. (69). Further studies 
highlighted that BB-DP rats harbored a microbiota characterized by lower levels of Bifidobacterium sp. and Lactobacillus sp. In comparison to control, diabetes free rats. Patterson et al. employed the streptozocin (STZ)-induced T1DM rat model to gain insights into the diabetes onset and progression in terms of microbiota shifts (70). T1DM was associated with changes in the Bacteroidetes: Firmicutes ratio while later T1DM progression was defined by elevated acid bacteria (i.e., Lactobacillus sp., Bifidobacterium sp.).

T1DM prone rats showed increased gut permeability and altered levels of the tight junction proteins claudin zonulin $(71,72)$. Within this context, a study employing the BB-DP rat model suggested that administration of Lactobacillus johnsonii N6.2 hindered diabetes development through regulation of gut integrity, specifically by modulating the tight junction protein claudin-1 (73). The knock out (KO) of myeloid differentiation primary response 88 (Myd88) (an adapter protein downstream of multiple TLR involved in sensing of microorganisms) in the NOD mouse protected against diabetes. Notably, heterozygous MyD88KO/+ NOD mice, which normally develop disease, were shown to be protected from diabetes when they were colonized from birth with the intestinal microbiota of a MyD88-KONOD donor mouse (74). Hence, disease progression in the NOD mouse is partially caused by an aggravated innate immune response to commensals and microbiota changes may counteract disease.

It has been shown that the altered microbiota of genetically obese mice is enough to promote increased adiposity in lean mice that receive a microbiota transplant. Moreover, the gut microbiota of obese people can lead to obese or adiposity phenotypes when transferred to mice (75).

Research carried out within the last few years has highlighted the features of the human diabetogenic microbiota (Figure 4).

As suspected, the studies demonstrated that microbiome profiles in diabetics were depending on ethnic origin, diet, geography, and age. However, in spite of these variations, some hallmarks could have been established. All research studies have highlighted Bacteroides sp. as a main culprit for type 1 diabetes mellitus (T1DM) associated dysbiosis (76).

It has been proved that Akkermansia muciniphila is more abundant in healthy individuals with normal weight than in individuals with obesity and T2DM (25). Furthermore, the Bacteroidetes: Firmicutes ratio was suggested as an early marker for autoimmune diseases since an enrichment of Bacteroidetes was reported in children who developed T1DM (77), but also for obesity and impaired glucose metabolism (78).

Individuals with both $\mathrm{T} 1 \mathrm{DM}$ and $\mathrm{T} 2 \mathrm{DM}$ were shown to be colonized by low levels of butyrate producers including Faecalibacterium prausnitzii, Roseburia intestinalis, Clostridium sp., Eubacterium rectale, and Faecalibacterium sp. (79) and of mucin degrading bacteria such as Akkermansia sp. and Prevotella sp. $(77,80,81)$. A study that analyzed Scandinavian postmenopausal women revealed lower levels of Faecalibacterium prausnitzii and Roseburia intestinalis in T2DM compared with individuals having impaired glucose tolerance.

Kostic et al. (82) analyzed 33 infants from Finland and Estonia who were genetically predisposed to diabetes and detected a relative $25 \%$ reduction in alpha-diversity in T1DM children but not in disease free seroconverters (82).
T1DM subjects were shown to have a microbiota with an elevated level of "pathobionts" that are commensal bacteria with a pathogenic potential, such as members of Blautia sp., Rikenellaceae, Ruminococcus sp. and Streptococcus sp. In addition, a depletion of Lachnospiraceae and Veillonellaceae, commonly encountered in inflammatory conditions was also evident. Recently, De Groot et al. (83) showed that fecal samples of T1DM patients were enriched in Christensenella and Bifidobacterium and low in SCFA producers like Roseburia (83). The human T2DM intestinal microbiota was shown to be inhabited by opportunistic pathogens including the sulfate-reducing genus Desulfovibrio, Escherichia coli, and Bacteroidaceae.

A Chinese study reported an increase of Escherichia coli in T2DM patients while a Danish study reported elevated Proteobacteria in T2DM (84). The bacterial counts of the L. acidophilus, L. plantarum, and L. reuteri subgroups of Lactobacillus sp. were significantly lower among Romanian patients with T2DM and obesity compared to healthy controls (85). A study performed on Romanian subjects revealed that the most common aerobic/facultative anaerobic species isolated from the stool cultures of 100 patients with metabolic syndrome, such as dyslipidemia, diabetes, and obesity were the Gram-negative (86). These Gram-negative bacteria may be linked to T2DM pathophysiology through the release of lipopolysaccharides (LPS) that promote a subclinical proinflammation which typical to diabetes and obesity. The so-called metabolic endotoxemia was firstly described in mice $(87,88)$ and defined as increased plasma levels of LPS, which are first bound by CD14 (cluster of differentiation 14), then recognized by the Toll like receptor 4 (TLR4) and thereafter, the formed LPS/CD14/TLR4 complex is taken up into chylomicrons, promoting systemic inflammation and subsequently inducing insulin resistance $(2,75,89)$. Bacterial peptidoglycans and LPS are also recognized by specific receptors of intestinal dendritic cells, such as Nucleotide-binding oligomerization domaincontaining protein 1 (NOD1), CD14 and TLR-4, inducing mucosal inflammation and bacterial translocation, by activating the nuclear factor $\mathrm{kB}(\mathrm{NF}-\kappa \mathrm{B})$ pathway (90). The term of metabolic infection has recently emerged in order to describe the role of the microbiota endotoxemia associated inflammation together with insulin resistance in T2DM (91). Another mechanism of increased intestinal permeability is represented by the reduced expression of epithelial tight junction proteins, including zonulin occluding (92). Zonulin levels are associated to changes in tight junction and altered intestinal permeability, allowing the invasion of antigens from intestinal environment, leading to inflammation and increased oxidative stress (62) (Figure 5).

Recent molecular studies indicated the presence of Methanobrevibacter smithii in the human gut, with variable prevalence, increasing with age, whereas a metaanalysis showed that the obese individuals had a fewer Methanobrevibacter sp. than non-obese ones. These results imply that obesity is associated to a different gut microbiota pattern (75).

Furthermore, several studies have characterized gut microbiota in obese subjects. The Roux-en- $\mathrm{Y}$ gastric bypass 


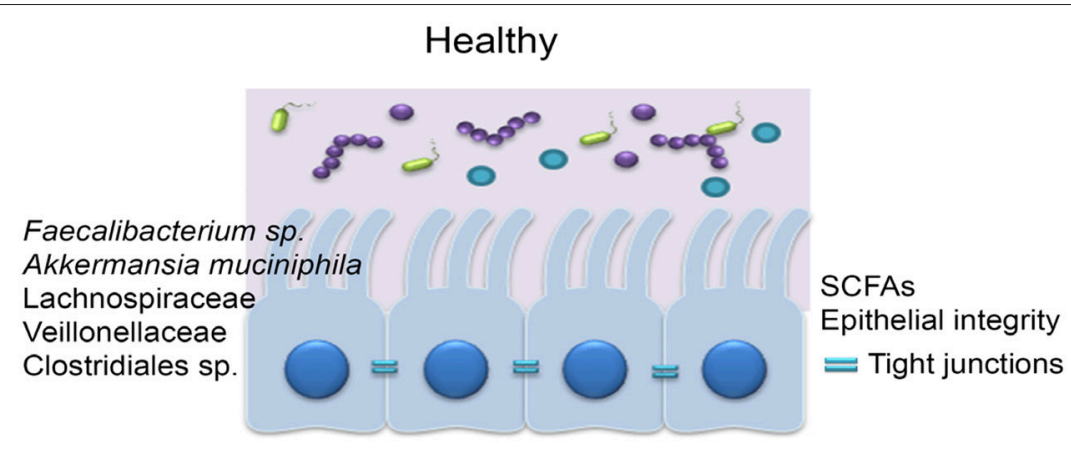

Type 1 diabetes

Type 2 diabetes

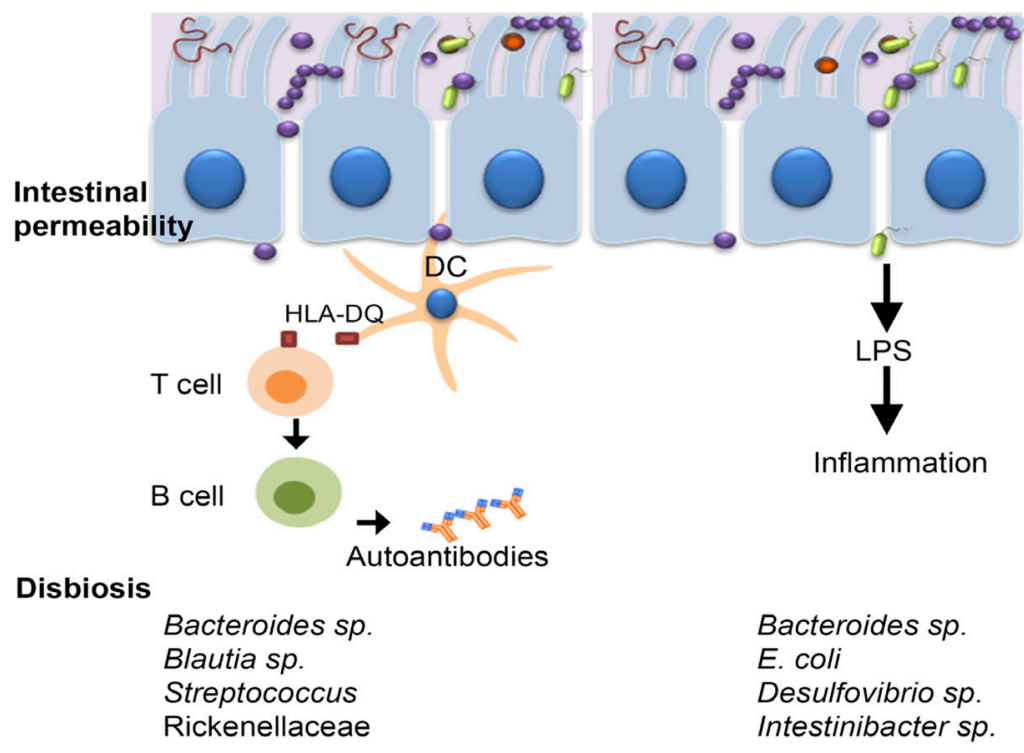

FIGURE 4 | The microbiota of diabetic patients. Individuals with diabetes were reported to have an impaired gut barrier function, characterized by a thinner mucus layer, and increased intestinal permeability. T1DM is an autoimmune disease caused by T-cell-mediated destruction of insulin-producing $\beta$-cells, the main genetic predisposition being the human leucocyte antigen (HLA) DR3-DQ2 and DR4-DQ8 haplotypes. Other factors including diet, antibiotic administration, infections, birth delivery mode have all been linked to T1DM development, however the mechanisms involved are not clear. The microbiota of T1DM patients is enriched in bacteria such as Bacteroides sp., Blautia sp., Streptococcus sp., and Rikenellaceae and low in butyrate producing bacteria, such as Faecalibacterium prausnitzii and mucin degrading bacteria (i.e., Akkermansia muciniphila). In case of T2DM, disease is generally triggered by lifestyle choices (unbalanced diet characterized by a high intake of refined sugar and saturated fats, sedentarism); individuals with T2DM harbor a microbiota characterized by elevated levels of Bacteroides sp., Intestinibacter sp, Escherichia coli, and Desulfovibrio sp.

(RYGB) is a powerful treatment for weight loss and improvement of metabolic status. Furet et al. (93) have analyzed the gut microbiota in fecal samples before and after RYGB. The Bacteroides/Prevotella group had a low abundance in obese subjects before and increased 3 months (M3) after RYGB; the abundance of Escherichia coli cells also increased at M3 and was inversely correlated with leptin levels and fat mass regardless of food intake. Also, lactic acid bacteria including Lactobacillus/Leuconostoc/Pediococcus group and Bifidobacterium sp. and were lower at M3 (93).

It has been demonstrated that stool transplant from a lean, insulin-sensitive donor to insulin-resistant obese men showed that insulin sensitivity of a subset of participants was significantly improved 6 weeks after the transplant (94).

\section{Influence of Diet on Gut Microbiota in Diabetes and Obesity}

Diet is one of the major lifestyle factors involved in the genesis, prevention and control of diabetes, obesity and other cardiometabolic diseases, being also strongly linked to changes in microbiota. Many reports have shown that the genetic susceptibility to obesity may have interacted with an obesogenic environment (e.g., a major shift in dietary patterns influencing the gut microbiota, a sedentary lifestyle and physical inactivity) in determining the obesity epidemic (23). To date, there are many popular diets including Mediterranean, gluten-free, vegan, Western, omnivore, vegetarian. To date, most of these diets have been clearly linked to different microbiome profiles (95). For instance, gluten free diet is characterized by low Bifidobacterium 


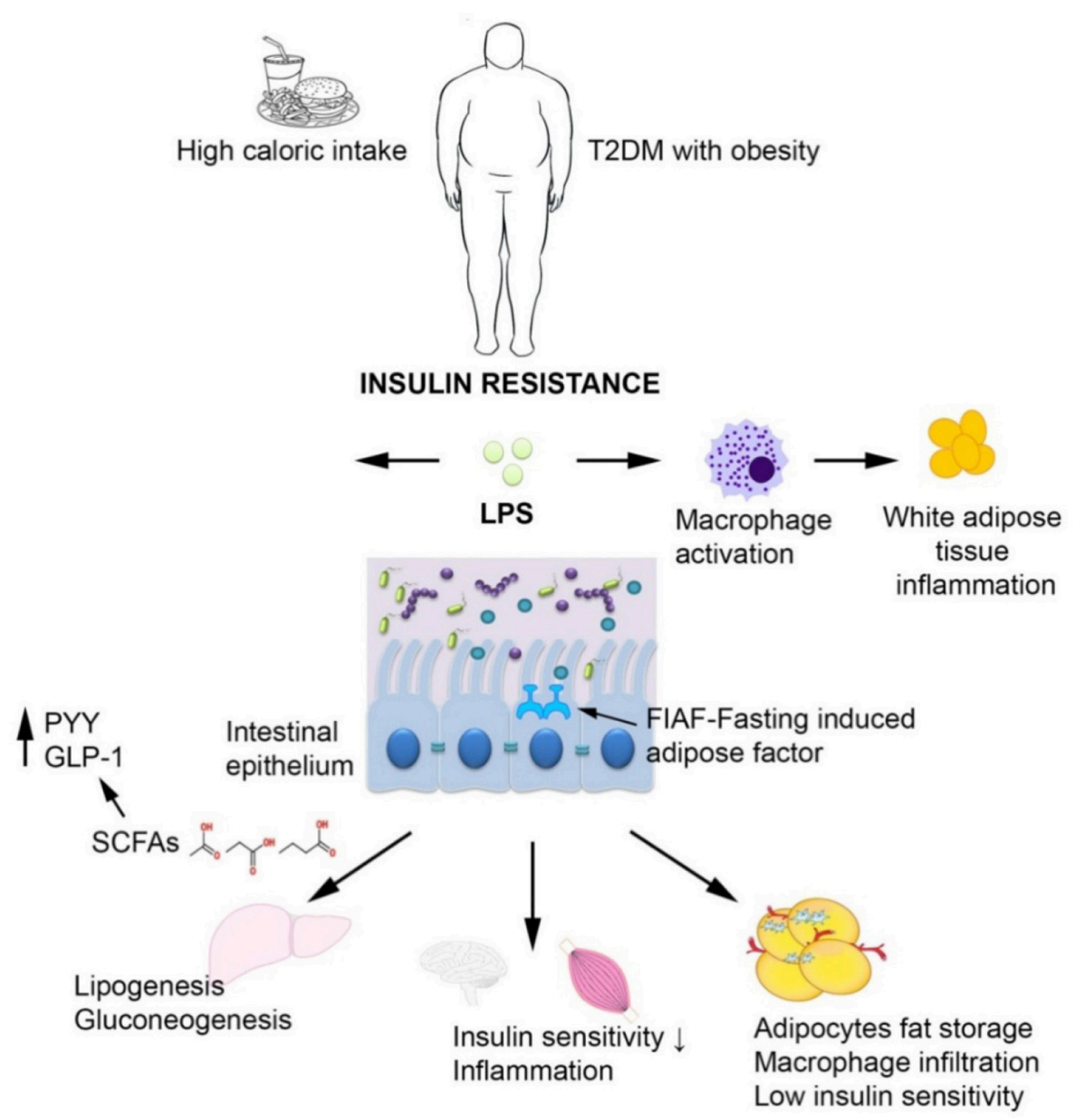

FIGURE 5 | The interplay between T2DM, obesity and the intestinal microbiota. In case of T2DM and obesity, increased intestinal permeability may trigger chronic bacterial translocation which in turn leads to systemic inflammation characterized by macrophage influx into the visceral adipose tissue, insulin resistance, and hepatic Kupffer cells activation. The short-chain fatty acids produced by the microbiota normalize gut permeability and reduce free fatty acid production.

sp. and Lactobacillus sp., whereas pathobionts, such as E. coli and total Enterobacteriaceae, increased proportionally with the reduction in polysaccharide/fibers intake (96). In addition, a short-term gluten-free diet lead to diminished levels of Ruminococcusbromii and Roseburiafaecis and increased Victivallaceae and Clostridiaceae $(17,31)$.

The Western lifestyle countries, following the industrial revolution, underlined a nutritional transition from the traditional diet to a diet rich in heavily processed foods, fats, sugars, proteins, plus different additives, while remaining low in micronutrients and dietary fibers (also referred to as Western diet). Dietary fibers are essential for gut health due to their role in stimulation of the growth and/or activity of certain beneficial microorganisms (97). People in traditional societies, with a fiber intake of almost 50-120 g/day harbor a much more diverse gut microbiota, on its turn indicating a "good health" condition. SCFAs are found in lower amounts in individuals consuming a Western diet. Plant fibers are rich sources of polyphenols that are considered redox mediators, regulating the oxygen tension in the gut lumen, where it is considerably lower, in comparison with that of the gut mucosa, with sufficient high oxygen tension to inhibit growth of strictly anaerobic microbes; in the lumen the anaerobes are favored by high consumption of these non-digestible carbohydrates. A fiber-rich diet leads to an increase of microbial genes in obese patients (98). Several studies reported that a diet enriched in non-digestible carbohydrates modifies the gut microbiota by increasing probiotic bacteria such as bifidobacteria and lactic acid bacteria. Indeed, diets rich in whole grain and wheat bran promoted an increase in intestinal bifidobacteria and lactobacilli $(99,100)$. In addition, resistant starch and whole grain barley increased the abundance of Ruminococcus sp., E. rectale, and Roseburia sp., whereas FOS, polydextrose- and AOS-based prebiotics were shown to reduce Clostridium and Enterococcus species (95).

Western diet was correlated with a decrease in the total bacterial load and in beneficial commensals, such as Lactobacillus, Bifidobacterium and Eubacterium species. Conversely, subjects consuming vegan and vegetarian diets 
which are rich in fermentable plant-based foods were reported to have a microbiota characterized by a lower abundance of Bacteroides sp. and Bifidobacterium sp. (101).

The Mediterranean diet (vegetables, moderate consumption of poultry, olive oil, cereals, legumes, winenuts, fish and a low amount of red meat, dairy products, and refined sugars) provides beneficial effects through the elevated content in mono-unsaturated and poly-unsaturated fatty acids, as well as high levels of antioxidants, fibers and vegetable protein content $(102,103)$. The gut microbiota in individuals receiving Mediterranean diet is characterized by a high colonization by Lactobacillus sp., Bifidobacterium sp., and Prevotella sp., and low levels of Clostridium sp. (95), species which are associated with weight loss, improvement of the lipid profile and decreased inflammation.

Dietary proteins were reported to be involved in shaping the microbiota since 1977. Thus, individuals consuming a diet rich in beef had high levels of Bacteroides sp. and Clostridia and were low in Bifidobacterium adolescentis unlike individuals eating a meatless diet (104). Several studies have recently shown that diets including vegetarian whey/pea protein, and animal protein (meats, eggs, and cheese) are linked with microbial diversity (95). Consumption of animal-based protein was positively associated to a richness in bile-tolerant anaerobes, including Alistipes sp., Bilophila sp., and Bacteroides sp. (105).

As shown by animal studies, a high fat diet leads to the establishment of a microbiotalow in Lactobacillus intestinalis and high in Clostridiales, Bacteroidales, and Enterobacteriales (106). Studies in mice revealed the effects of different type of lipids on the microbiota. While lard-fed mice harbored increased numbers of Bacteroides sp. and Bilophila sp. and reduced levels of Desulfovibrio sp., those fed with fish oil had increased lactic acid bacteria (Lactobacillus sp. and Streptococcus sp.), Verrucomicrobia (A. muciniphila), and Actinobacteria (Bifidobacterium sp. and Adlercreutzia sp.) and mice fed with a diet rich in milk fat or supplemented with taurocholic acid (a biliary acid) showed increased levels of Bilophilawadsworthia (107). The fact that the type of fat used in one's diet has distinct impact on the microbiota was recently analyzed in a study by Prieto et al. (108). Indeed, a diet enriched with extra virgin olive oil (EVOO) harbored a different effect on the intestinal microbiota in comparison with an enriched butter diet (BT). Swiss Webster mice fed with BT exhibited the highest values of systolic blood pressure and increased abundance of Desulfovibrio whereas mice fed EVOO had the lowest values of plasmatic insulin and leptin and a significant increase in $B$. fragilis (108). It has also been shown in mice that shifting from a high-fat/low-fiber diet to a low-fat/high-fiber diet can alter microbiota composition within a day. Importantly, diet also depends on the enterotype, as subjects on a diet high in animal fat/carbohydrate-rich have Bacteroides-/Prevotelladominated enterotypes (109). Mice receiving high fat diet (HFD) until diabetes occurrence, developed endotoxemia, increased gut permeability and microbiota changes (110). The level of plasma endotoxins were higher in mice raised in conventional conditions fed with saturated fatty acids in comparison to animals fed with polyunsaturated fatty acids. Moreover, lard-fed mice exhibited white adipose tissue inflammation and impaired insulin sensitivity compared to fish oil-fed mice (111). In the adipose tissue, endotoxins activate TLRs, inducing the expression of chemokines required for macrophage infiltration (112). It is well established that the intestinal microbiota interacts with the innate immune system to trigger adipose inflammation, since mice deficient in TLRs signaling (through loss of the adaptor proteins MyD88 or TRIF-TIR-domaincontaining adapter-inducing interferon- $\beta$ ) showed reduced levels of inflammation in adipose tissue and were protected from saturated fatty acids induced insulin resistance $(111,113,114)$. Mice deficient in Myd88, but not for TRIF, are protected from diet-induced obesity, suggesting that obesity and insulin resistance are controlled by different mechanisms. The insulin resistance promoted by high-fat diet is correlated with increased levels of Th17 cells, involving gut microbiota, by the following mechanism: the fat-induced restriction of the commensal segmented filamentous bacteria determines the expression of IL-23 in enterocytes (115); IL-23 activates the release of IL-22 from innate lymphoid cells in the submucous ileal lymphoid folicles; IL-22 induces the production of the serum proteins amyloid A1 and A2, which are required for the activation of Th17 cells in the ileum. Unlike fat, fructose and glucose induce increased levels of diacylglycerols (DAG) which are mediators for insulin resistance in the liver. Ramos-Romero et al. demonstrated that GIT microbiota of rats receiving an excess of fats and sugars in their diet has shown elevated levels of Enterobacteriales and Escherichia coli, the combination of fats and sugars proving more harmful than fat or sugar alone when taken in excess (116).

A high protein consumption elevates insulin-like growth factor 1 (IGF-1), proved to be linked to a high diabetes risk (117). Ley et al. (78) found that genetically obese ob/ob animals fed with polysaccharide-rich diet have a $50 \%$ decrease in the quantity of Bacteroidetes and a proportional Firmicutes increase in cecal microbiota, this trait being transmissible.

Comparative studies performed on germ-free and conventional mice have demonstrated that after receiving a Western-style diet, germ-free mice exhibited reduced adiposity and improved insulin and glucose tolerance compared to conventional counterparts (118). The colonization of germ-free mice with microbiota from conventionally-raised mice lead to a significant increase in insulin resistance and body fat (64).

\section{Diet-Microbiota Interactions in Patients With Diabetes and Obesity}

The role of diet in diabetes was highlighted decades ago by the observation that this disease was highly prevalent among rich people with easier access to food, such as white flour, refined sugar, and oils, animal fats ( \pm fried) (119).

Many research studies have highlighted a strong link between high sugar intake and T2DM development (120). Based on their capability to be degraded enzymatically in the small intestine, carbohydrates are either digestible (i.e., starch and sugars including glucose, lactose, fructose, sucrose) or non-digestible (resistant starch and fiber). After degradation, 
digestible carbohydrates release glucose into the bloodstream and lead to an insulin response (95). Their ingestion in high levels leads to a microbiota enriched in Bifidobacteria and low in Bacteroides (121). The addition of lactose to the previously mentioned diet replicated the same bacterial shifts but also decreased the levels of Clostridia (122). The high levels of fructose corn syrup used for the production of soft drinks increased the blood glucose levels and the body mass index thus linking the intake of soft drinks with obesity and T2DM (123). Moreover, diet soft drinks were reported to contain various glycated chemicals which promote increased insulin resistance (124). Ludwig et al. studied 500 ethnically diverse children for a period of 19 months and showed that the obesity frequency increased for every intake of carbonated soft drinks (125).

Artificial Sweeteners are still an intense subject of debate in the carbohydrate fields. Artificial sweeteners such as sucralose, saccharin, and aspartame were designed to be a healthier food additive aimed to replace natural sugar. However, recent work by Suez et al. showed that artificial sweeteners can lead to glucose intolerance faster than the glucose or sucrose. The effects produced by artificial sweeteners were attributed to the increased abundance of Bacteroides sp. and decreased Lactobacillus reuteri (126).

Contrary to digestible carbohydrates, non-digestible carbohydrates are digested in the colon where they undergo fermentation by commensals leading to the production of SCFAs. It has been shown that Faecalibacterium prausnitzii, a high SCFA producer is depleted in diabetic patients (127). When fed with high levels of resistant starch, individuals who did not harbor high Ruminococcus bromii also had the highest levels of undigested starch in the stool, suggesting that the microbiota composition determines carbohydrates accessibility to the microbiota. Cocoa products rich in polyphenols (e.g., flavonol) have been shown to help preventing cardiometabolic disorders, exhibiting antioxidant, anti-atherogenic, anti-depressant, antiinflammatory, antihypertensive, and anti-thrombotic effects, as well as influence on vascular endothelial function, insulin sensitivity and activation of nitric oxide (with protective role by relaxing the blood vessels and lowering blood pressure) (128). Clinical trials reported that dietary polyphenols increase the levels of Bifidobacterium sp. (129). Indeed, daily consumption of red wine polyphenols for 4 weeks significantly increased Bifidobacterium sp., Prevotella sp., Bacteroides sp., Eggerthellalenta, Enterococcus sp., Bacteroidesuniformis, and Blautiacoccoides-Eubacteriumrectale abundance compared with baseline (130). It has been shown that chocolate or cocoa reduced insulin and fasting insulin after glucose challenge and improved insulin resistance, while there was no change on fasting glucose and glycated hemoglobin (HbA1c) (131). Consumption of dark chocolate containing $500 \mathrm{mg}$ polyphenols for a period of 4 weeks lowered fasting glucose, blood pressure, and insulin resistance compared to $20 \mathrm{~g}$ of placebo dark chocolate with a negligible polyphenol content (132). Drinking cocoa flavanols (902 mg) for 12 weeks also enhanced insulin sensitivity in overweight and obese people compared to a low-flavanol cocoa drink (133). However, daily consumption of $25 \mathrm{~g}$ dark chocolate for 8 weeks did not improve insulin, fasting glucosea and HbA1c levels in hypertensive diabetics compared to those who served $25 \mathrm{~g}$ of white chocolate (134). Several studies have reported the positive effects of cinnamon on glycemic control. Importantly, cinnamon contains polyphenols (e.g., cinnamtannin, transcinnamic acid procyanidin), flavones (cinnamaldehyde and trans-cinnamaldehyde), and catechin (129). Even though clinical studies showed positive effects of cinnamon on fasting blood glucose levels, there were no significant changes in HbAlc, HDL, LDL or total cholesterol $(135,136)$. Other reports showed no significant changes in fasting glucose, HbA1c or insulin levels in the case of 43 subjects with T2DM receiving $1 \mathrm{~g}$ of cinnamon daily for a period of 3 months (137), 25 post-menopausal women with T2DM taking cinnamon ( $1.5 \mathrm{~g} /$ day) for 6 weeks (138), 11 healthy subjects taking cinnamon (3 g daily) for 4 weeks (139), and in 72 adolescents with T1DM taking $1 \mathrm{~g}$ of cinnamon daily (140). A clinical trial using 58 subjects with T2DM reported that $2 \mathrm{~g}$ of daily cinnamon intake for a period of 12 weeks significantly reduced $\mathrm{HbA1c}$ and blood pressure (141). Supplementation with $500 \mathrm{mg}$ olive leaf extract for 14 weeks inT2DM patients significantly reduced $\mathrm{HbAlc}$ and fasting insulin but had no impact on post-prandial insulin levels (142). Resveratrol supplementation in obese men for 1 month reduced glucose, insulin resistance index and leptin level and lowered inflammatory markers (e.g., TNF- $\alpha$, leukocytes). Even though resveratrol supplementation also reduced plasma fatty acid and adipose tissue lipolysis in the post-prandial state (143), the study lacked some of the necessary controls; therefore more investigations are required in order to prove that resveratrol holds antidiabetic effects.

Whole grains including soy, rye, wheat, and flaxseed and nuts such as almonds, pecans, and hazelnuts are also a high source of polyphenols (144). Whole grain intake was linked to a decreased risk of T2DM but the mechanism of the protection is not well known (145). Moreover, individuals show large variations in glucose metabolism in response to an intervention based on whole grains. Thus, eating whole grains for a period of 3 days improved glucose tolerance in some responder subjects that revealed an increased prevalence of certain glycoside hydrolases within their microbiome compared to the non-responder subjects. This suggests that the gut microbiota may need to already hold the ability to degrade specific complex dietary carbohydrates. Importantly, individuals whose microbiota a responded to a whole-grain intervention had the tendency to have high fiber diets. Thus, the complex carbohydrates linked to whole grains and metabolically accessible to the responders microbiota were probably inaccessible to nonresponder individuals who also did not usually consume diets rich in fiber. Improved glucose tolerance in case of the responders may be due to the enrichment of Prevotella sp.. Prevotella sp. may also improve glucose metabolism in mice fed diets rich in carbohydrates instead of high-fat diets (146).

Olive leafs and extra virgin olive oil are a source of polyphenols, such as hydroxytyrosol and oleuropein with beneficial effects in T2DM (130).

The Mediterranean diet supplemented with nuts or virgin olive oil harbored anti-inflammatory effects by decreasing chemokines, IL-6, T-lymphocytes, monocytes and adhesion 
molecules (147). A study performed on patients with high cardiovascular risk showed that a Mediterranean diet rich in extra virgin oil led to a $40 \%$ decrease of T2DM risk compared to the control (148). Addition of olive leaf polyphenols ameliorated insulin sensitivity and pancreatic $\beta$-cells secretory capacity after oral glucose challenge in middle aged overweight men with risk of developing metabolic syndrome $(149,150)$.

Several studies in humans indicate that following a vegan diet for at least 6 months or a high-fiber-low-fat diet for 10 days were insufficient to substantially increase microbiota diversity or production of fecal SCFAs.

Even though it may promote a greater weight loss, a protein rich diet can also be detrimental. In this sense, individuals on a high protein/low carbohydrate diet harbored a microbiota with diminished levels of Roseburia sp. and Eubacterium rectale, but low levels of butyrate in their feces (151). In addition, elevated intake of red meat has been linked to elevated levels of the proatherogenic microbial metabolite TMAO (152). Also, its precursors such as betaine was also associated with cardiovascular diseases and T2DM.

Animal-based diets are also high in fat. An association between fat intake and the subsequent risk of developing T2DM has been reported. A study which enrolled more than a thousand individuals without a prior diagnosis of diabetes reported a relationship among T2DM, fat intake, and impaired glucose tolerance. Consumption of high saturated and transfat diets elevates cholesterol levels and is linked with a risk of cardiovascular disease, Conversely, mono and polyunsaturated fats lower the risk of chronic disease development (153). Importantly, high-fat diets enrich the abundance of Bacteroides sp. as well as of total anaerobic microorganisms $(109,154)$. Consumption of a low fat diet leads to the over-abundance of Bifidobacterium sp. and a reduction of fasting glucose and total cholesterol, while a high saturated fat diet determines a microbiota enriched in Faecalibacterium prausnitzii (155).

\section{Nutrigenomics and Nutrigenetics in the Context of the Gut Microbiota-Host Metabolism-Diet Trialogue}

Recently, nutrigenomics and nutrigenetics have emerged due to the need for a holistic pathway combining genetics, nutrition, metabolism, and "omic" technologies to analyze the intricate relationships between environmental factors relevant to metabolic health and disease status. These emergent fields of nutritional science hold promise in advancing nutrition for optimal individual and public health, being carefully supervised by the International Society of Nutrigenetics/Nutrigenomics (156). Nowadays, personalized nutritional interventions are regarded as crucial factors in preventing or reversing the epidemic features of T2DM and obesity, as well as of other chronic diseases (157).

Based on current views, personalized nutrition occurs at three levels: (i) conventional nutrition based on general guidelines for population groups based on age, gender, and social determinants; (ii) individualized nutrition that takes into account the phenotypic information regarding the person's current nutritional status (e.g., anthropometry, physical activity biochemical, and metabolic analysis), and (iii) genotype-directed nutrition based on a rare or a common gene variation (156).

Certain food ingredients, environmental pollutants, and drugs can induce epigenetic changes related to the occurrence of diabetes and obesity, transmissible to subsequent generations (30, 158). Animal and human studies have shown that the nutritional status in one generation can change the epigenetic profiles in subsequent generations, thus having an evident effect on children health. Within this line of thought, nutrients such as niacin, flavonoids, folate, selenium, and choline are only a few examples. In addition, high-fat diets and maternal protein restriction produce a negative effect on the epigenetic regulation of genes by altering their DNA methylation status, dictating the quick adaptation to available food. As obesogenic diets, high- in fat and calorie-dense foods are unfortunately the most available for the general population, hence, they will be overconsumed not only by the current generation, but also by the subsequent generations, "instructed" to seek and consume the "most available" diet (158).

Obesogenic diets lead to remarkable differences between siblings despite their identical genotype. Studies on primates or rodents reported that an obesity-promoting, calorie-dense maternal diet epigenetically changed the fetal chromatin structure by producing covalent modifications of histones. Maternal food restriction during pregnancy, as well as the nutritional status of grandparents altered the DNA methylation status of genes involved in the pathogenesis of obesity, diabetes or cardiovascular events in subsequent generations $(30,159)$. Other studies indicated that weight status (as an indicator of food intake) modified the risk of disease in subsequent generations (160). Maternal obesity- or malnutrition-related exposures at the very early development, even prior conception, usually reveal a positive association with congenital anomalies, related to abnormal methylation patterns (161). Obesity of the father was also linked with aberrant low methylation patterns in the offspring (162).

LMW metabolites and signal molecules generated by the indigenous gut and vaginal microbiota of pregnant women can cross the placenta and reach the fetus, affecting its development, metabolism, cognitive function and body composition in the natal and post-natal periods of life through the epigenetic modulation of gene expression (30). This information suggests that significant modifications in the maternal indigenous microbiota may produce long-term metabolic consequences in the offspring which subsequently may affect adult health and life span as a result of epigenetic modifications. Providing pregnant women with an appropriate diet, prebiotics, probiotics, and/or bioactive supplements (enzymes, relevant cofactors, or their precursors) will restore the intracellular concentrations of signal molecules necessary for the epigenetic modulation of chromatin, DNA, and histones or alteration of post-translated products (163).

Even though dietary interventions impact the metabolic host response in an individual manner, analysis of the microbiome can aid to predict the response and moreover, orient the selection of therapeutic interventions (e.g., probiotic strains able 
to metabolize specific dietary components toward getting a desired effect) (164).

\section{THERAPEUTIC INTERVENTIONS TRIGGERING THE GUT MICROBIOTA}

While governments and health organizations are engaged to discover treatment options for largely preventable diseases, an emerging research area targeting the microorganisms inhabiting the digestive tractis providing new insights and possible ways for intervention.

\section{Probiotics}

Nowadays, probiotics are highly investigated for their effects on host health and, in addition, intensive research is being done to select novel strains with probiotic potential (165169). Probiotics have anti-inflammatory, hypoglycemic, insulinotropic, antioxidative, and satietogenic properties, thus they can be employed in the treatment of T2DM and obesity (170).

The multiple protective mechanisms of probiotics in T2DM treatment were reported by several studies using animal models. Oral inoculation $(0.05 \%)$ or diet supplementation $(0.1 \%)$ of heatkilled Lactobacillus casei in several mouse models including KK-Ay mice, NOD mice, and Alloxan-induced diabetic mice led to reduced plasma glucose level and diabetes development $(171,172)$. Neonatal STZ-induced diabetic (n-STZ) rats that were fed with a diet containing Lactobacillus rhamnosus GG for 9 weeks exhibited lower blood hemoglobin levels and an improved glucose tolerance compared to the control group fed with a conventional diet. The group that received L. rhamnosus $G G$ harbored a serum insulin level significantly higher than in the control group just $30 \mathrm{~min}$ after glucose loading (173). Feeding NOD mice with the multispecies probiotic VSL\#3 led to increased IL-10 secretion in Peyer's patches, pancreas, and spleen and lowered $\beta$-cell destruction and inflammation. Several reports highlighted that oral administration of probiotics to diabetic rats significantly improved hyperglycemia, oxidative stress, and dyslipidemia.

In fructose-induced diabetic rats of the use of a probiotic containing Lactobacillus acidophilus NCDC14 and Lactobacillus casei NCDC19 significantly decreased glycosylated hemoglobin, free fatty acids, blood glucose, and triglycerides (174). Feeding the same probiotic to STZ-induced rats abolished the oxidative damage induced by STZ in pancreatic tissues through inhibition of nitric oxide release and lipid peroxidation and also enhanced the antioxidant potential of catalase, glutathione, superoxide dismutase, and glutathione peroxidase (175). In alloxan induced diabetic rats, probiotic pre-treatment employing a mixture containing Bifidobacterium lactis, Lactobacillus acidophilus, and Lactobacillus rhamnosus lead to lower blood glucose and elevated the bioavailability of gliclazide, a sulphonylurea used for treating non-insulin dependent T2DM $(176,177)$. The antidiabetic effects against insulin resistance of different probiotics may also be due to increased hepatic natural killer T (NKT) cells. Depletion of NKT cells determined enhanced secretion of proinflammatory cytokines, whereas HFD was reported to induce depletion of hepatic NKT cells, thus leading to insulin resistance in C57BL/6 mice. Nevertheless, administration of VSL\#3 led to reduced insulin resistance, weight loss, and improved inflammation, by modulating NF-kB (178). In HFD fed C57BL/6 J mice, as well as in STZ-induced diabetic rats, Lactobacillus plantarum DSM 15313 and Lactobacillus reuteri GMNL-263 lowered glycosylated hemoglobin and blood glucose $(179,180)$. Dendritic cells (DCs) from NOD mice were stimulated with Lactobacillus casei, Lactobacillus reuteri, or Lactobacillus plantarum for a 1 day and out of the strains tested, Lactobacillus casei induced the highest level of IL-10. Subsequently, when the Lactobacillus caseistimulated DCs were transferred to NOD mice, the recipients revealed a significant delay in diabetes incidence (181).

In HFD fed mice, the administration of Bifidobacterium animalis subsp. lactis 420 improved insulin sensitivity and fasting hyperinsulinemia and also reduced the bacterial translocation to mesenteric adipose tissue, lowering the expression of IL6 , TNF- $\alpha$, and IL-1 $\beta$ in mesenteric adipose tissue, liver, and muscles (90). A novel study by Lee et al. analyzed the antidiabetic effects of Lactobacillus plantarum $\operatorname{Ln} 4(\operatorname{Ln} 4)$, which was obtained from napa cabbage kimchi. The oral administration of Ln4 reduced epididymal fat mass and weight gain, lowered plasma triglyceride levels and the insulin resistance index in HFD fed mice (182). It has been shown that among probiotic bacteria, only Lactobacillus plantarum and several selected strains within the genus Bifidobacterium (mostly Bifidobacterium adolescentis and Bifidobacterium pseudocatenulatum) are capable of in vivo folate production. Therefore, the use of folateproducing probiotic strains could more effectively confer protection against inflammation (183). Since there are only a few studies available, the role of probiotics in diabetic human subjects is still largely unknown. Several randomized, double blind, placebo controlled (RDBPC) clinical trials investigated the effects of probiotic administration on antioxidant status, blood glucose, and lipid profile in T2DM. The probiotic intervention group consumed $300 \mathrm{~g} /$ day of probiotic yogurt containing $10^{6}$ $\mathrm{CFU} / \mathrm{ml}$ Lactobacillus acidophilus La5 and $10^{6} \mathrm{CFU} / \mathrm{ml}$ B. lactis $B b 12$ whereas the control group consumed the same dose of conventional yogurt for 6 weeks. The probiotic treatment cohort showed as an increase in the activities of the glutathione peroxidase and a significant decrease in fasting blood glucose. The total cholesterol: HDL ratio and LDL-C:HDL-C ratios were also lower in the probiotic treatment group, compared to the control $(184,185)$. A randomized clinical trial that enrolled 450 patients with T2DM and hyperlipidemia was recently performed by Tong et al. The group tested the hypothesis that gut microbiota alteration may be involved in the mitigation of T2DM with hyperlipidemia by using metformin and a specifically designed herbal formula. Metformin and the herbal formula were shown to ameliorate T2DM with hyperlipidemia by enriching beneficial bacteria, such as Blautia and Faecalibacterium spp (186). The effects of maternal dietary counseling during pregnancy were investigated in a RDBPC study by Luoto et al. (187). Within this study, 256 pregnant women were randomized into three treatment groups: a control cohort (control/placebo), dietary intervention with probiotics (diet/ Lactobacillus rhamnosus 
$G G$ and B. lactis), and with placebo (diet/placebo). The study revealed that the probiotic supplement increased the colostrum adiponectin concentration compared to the control. A recent study by Kijmanawat et al. revealed that 4 weeks supplementation using a probiotic containing Bifidobacterium and Lactobacillus in women with diet-controlled gestational diabetes in the late second- and early third-trimester lowered fasting glucose and increased insulin sensitivity (188). A recent clinical study by (189), showed that probiotic supplementation (containing L. casei $2 \times 10^{9}$, Bifidobacterium bifidum $2 \times$ $10^{9}$, L. acidophilus $2 \times 10^{9} \mathrm{CFU} /$ day) for a period of 12 weeks had beneficial effects on biomarkers of inflammation in diabetic patients with coronary heart disease (CHD) as well as on glycemic control, HDL-cholesterol, total-/HDL-cholesterol ratio, and oxidative stress (189). Administration of a multi-strain probiotic supplementation over 6 months as a monotherapy lead to significantly lower HOMA-IR in T2DM patients, with inflammation and an improved cardiometabolic profile (190).

Importantly, patients with diabetes are often faced with major depression leading to more diabetic complications, poorer selfcare, and lower medication adherence (191). Within this line of thought, probiotics have been administered to diabetics with depression. Vitamin D and probiotic (Lactocare Zisttakhmir Co) co-supplementation for a period of 12 weeks among diabetic people with CHD harbored positive effects on mental health parameters, HDL-cholesterol level, glycemic control, and total antioxidant capacity (192).

However, other studies state that probiotic use does not provide a significant benefit for the diabetic patients. For example, a randomized, double-blinded clinical trial using Lactobacillus acidophilus NCFM in 45 men for a period of 4 weeks reported that there were no changes in the expression of baseline inflammatory markers and in the systemic inflammatory response after probiotic treatment (193). Recently, Kobyliak et al. (194), showed that probiotic therapy consisting of a concentrated biomass of 14 probiotic bacteria genera Bifidobacterium, Lactobacillus, Lactococcus, Propionibacterium had a modest effect on insulin resistance in patients with type 2 diabetes (194).

\section{Prebiotics}

As a source of SCFAs, prebiotics may improve glucose tolerance. Prebiotics were also suggested to reduce hypercholesterolemia through lowering of cholesterol absorption as well as by inducing SCFAs production by commensals $(195,196)$. The intake of the prebiotic inulin (20 g/day) significantly lowered serum triglycerides, increased serum HDL-cholesterol, and decreased serum LDL-cholesterol compared to the control group (197). In addition, normolipidemic individuals consuming daily $18 \%$ of inulin without any other dietary restrictions exhibited a lowering in triacylglycerols and total plasma cholesterol as well as elevated fecal concentrations of Lactobacillus-lactate (198). In rats, the addition of inulin to diet, increased the fecal excretion cholesterol and lipids compared to the control group, due to a lower cholesterol absorption (199). Other prebiotics including oligodextrans, lactose, resistant starches, lactoferrinderived peptides, and $\mathrm{N}$-acetyl-chito-oligosaccharides were also reported to have hypocholesterolaemic effects in T2DM patients at risk to develop cardiovascular complications (200). A diet rich in arabinoxylan and resistant starch lead to increased Bifidobacterium and butyrate levels in patients with metabolic syndrome (201).

Due to their cost, availability and lack of acute toxicity, dietary polysaccharides may be employed alone or in combinations, to improve human health in various health conditions. Using prebiotics in synbiotic products, besides their role in stimulating the expansion of probiotics, they also inhibit pathogen growth, stimulate immunity, and vitamins synthesis. A RDBPC study that enrolled 20 diabetic volunteers aged 50-60 years, for a time frame of 30 days analyzed the effects of a synbiotic drink (a combination of probiotics and prebiotics) on blood glucose and cholesterol levels. The symbiotic treatment group consisted of patients that consumed $10^{8} \mathrm{CFU} / \mathrm{mL}$ Bifidobacterium bifidum, $10^{8} \mathrm{CFU} / \mathrm{ml}$ of Lactobacillus acidophilus, and $2 \mathrm{~g}$ oligofructose harbored increased HDL cholesterol, and decreased fasting glycemia; but, importantly, no significant changes were observed in the placebo group (202).

\section{CONCLUSIONS AND PERSPECTIVES}

The complex molecular and cellular interactions established between the gut microbiota and the host, starting immediately or even before birth (as stated in some recent studies), have a key role in host homeostasis. Any disorder of the "healthy" gut microbiome induced by infections, changes in the lifestyle, diet or use of antimicrobial substances can result in a plethora of pathologies, such as chronic gastrointestinal diseases, neurological disorders, autoimmune diseases, allergies, diabetes, obesity, cardiovascular diseases, chronic inflammation or cancer. The high biodiversity within the microbiota may act as an important marker of eubiosis. The capacity to access and remodel the composition and function of the microbiota makes it an attractive target for establishing a link between certain patterns of gut microbiota and physiology/pathology status. This paves the opportunity for development of potential biomarkers, and new tools for prevention, screening and treatment in personalized healthcare strategies. Nevertheless, due to the complexity and individuality of human microbiota, a challenge at present time is the identification of microbial patterns and microbial metabolic pathways specifically linked to health or disease. In this regards it is critical to establish the profile, if any, of a normal gut microbiome.

There are many studies linking an altered gut microbiota with metabolic diseases from obesity to T2DM and cardiovascular diseases. Members of the indigenous microbiota may regulate body weight via the modulation of the host metabolism, immunity and neuroendocrine functions. The gut microbiota provides metabolic functions and is involved in regulating host gene expression, influencing the ability to extract and store energy from dietary sources. Moreover, obese individuals with lower bacterial richness/dysbiosis have been shown to have greater weight gain, while microbiota transplantation of either obese or lean mice in germ-free recipients influences body 
weight, suggesting that the intestinal ecosystem is a powerful tool for weight management.

However, there are still questions and hypotheses waiting to be confirmed or disapproved by future studies, such as: can intestinal microbiota be a target in the treatment of diabetes and obesity? Can the transplant of human normal, "healthy" intestinal microbiota to another human with dysbiosis or "decompensated" intestinal microbiota be possible as a therapeutic measure?

Prospective studies on large cohorts of participants using high-resolution monitoring of host and microbial parameters assessed by omics approaches are needed to determine if the microbiota is altered prior or after disease onset. A multi-parameter individual approach, including microbiota analysis will provide information regarding the characteristics of people responding positively to a given intervention. A deeper understanding of the gut microbiota could essentially contribute to the management of metabolic health and weight loss paving the way for microbiota-focused precision nutrition.

Experiments of microbiota transplantation from humans to mice could highlight the microbial species responsible for the occurrence of obese phenotype vs. protective species, such as Christensenellaminuta, specific metabolic pathways (e.g., biosynthesis of branched-chain amino acids, which linked to impaired sensitivity to insulin vs. SCFAs pathway), microbial metabolites (detrimental vs. beneficial), or diets (high fat vs. high in fruits and vegetables; low vs. rich in fibers).

A better knowledge of the interactions between the host and gut microbiota is also needed in order to increase the predictability of the experimental models. Studies performed exclusively on fecal samples could not be indicative about the processes occurring in the small intestine, which are essential for vitamin absorption. Intestinal microbiota can be directly modulated by the use of probiotics, prebiotics, and even antibiotics. The use of antibiotics in early life is correlated with obesity in both humans and mice. Antibiotics can be used for treating certain GIT ailments, but the microbiota alterations they induce may promote metabolic disturbances, changes in intestinal permeability, susceptibility to infections,

\section{REFERENCES}

1. Sekirov I, Russell SL, Antunes LC, Finlay BB. Gut microbiota in health and disease. Physiol Rev. (2010) 90:859-904. doi: 10.1152/physrev.00045.2009

2. Sonnenburg JL, Bäckhed F. Diet-microbiota interactions as moderators of human metabolism. Nature. (2016) 535:56-64. doi: 10.1038/nature18846

3. Clemente JC, Ursell LK, Parfrey LW, Knight R. The impact of the gut microbiota on human health: an integrative view. Cell. (2012) 148:1258-70. doi: 10.1016/j.cell.2012.01.035

4. Qin J, Li R, Raes J, Arumugam M, Burgdorf KS, Manichanh C, et al. A human gut microbial gene catalogue established by metagenomic sequencing. Nature. (2010) 464:59-65. doi: 10.1038/nature08821

5. The Human Microbiome Project Consortium. Structure, function and diversity of the healthy human microbiome. Nature. (2012) 486:207-14. doi: $10.1038 /$ nature 11234 especially fungal ones and an increased risk of Clostridium difficile infection.

Increased polysaccharides levels are likely to be beneficial for individuals eating a typical Western-style, fiber-poor diet. Beneficial metabolites such as butyrate or the bacteria that produce them could be supplemented pharmacologically, while receptor antagonists or enzymatic inhibitors could be developed for detrimental metabolites, such as TMAO. However, controlled dietary interventions that document the utility of various nutrients, supplements, probiotics, and foods in regulating aspects of the microbiota and human health are required. Dietary interventions need to be individually adjusted to prevent or treat chronic diseases based on the genetic background, food and beverage consumption, nutrient intake, microbiome, metabolome, and other omics profiles.

As a general purpose, we can achieve eubiosis and host health by reducing the antimicrobials consumption and assuring the necessary nutrients, respecting everyone's preferences, by a diverse and balanced diet containing macroand micro-nutrients.

\section{AUTHOR CONTRIBUTIONS}

VL designed and wrote the manuscript. L-MD wrote the manuscript. GP designed all the figures, wrote part of the manuscript and submitted the paper. AP, LP, and NC wrote the manuscript. MC drafted and revised the manuscript.

\section{FUNDING}

Research Grant PN III-P2-2.1-BG-2016-0369-116/2016.

\section{ACKNOWLEDGMENTS}

The financial support of the research project: Professional training of medical personnel in medical Genetics/Formarea Profesională a personalului medical în Genetică medicală-PROGEN-SMIS107623 Contract no. POCU: 91/4/8/107623/08.12.2017 and Research Grant PN 1ll-Pz-z.1-BG-2016-0369-1 1612016 is gratefully acknowledged.
6. Frank DN, St Amand AL, Feldman RA, Boedeker EC, Harpaz N, Pace NR. Molecular-phylogenetic characterization of microbial community imbalances in human inflammatory bowel diseases. Proc Natl Acad Sci USA. (2007) 104:13780-5. doi: 10.1073/pnas.0706625104

7. Hugon P, Dufour JC, Colson P, Fournier PE, Sallah K, Raoult D. A comprehensive repertoire of prokaryotic species identified in human beings. Lancet Infect Dis. (2015) 15:1211-9. doi: 10.1016/S1473-3099(15)00293-5

8. Mikelsaar M, Lazar V, Onderdonk AB, Donelli G. Do probiotic preparations for humans really have efficacy? Microbial Ecol Health Dis. (2011) 22:10128. doi: 10.3402/mehd.v22i0.10128

9. Arumugam M, Raes J, Pelletier E, Le Paslier D, Yamada T, Mende DR, et al. Enterotypes of the human gut microbiome. Nature. (2011) 473:174-80. doi: 10.1038/nature09944

10. Zhernakova A, Kurilshikov A, Bonder MJ, Tigchelaar EF, Schirmer M, Vatanen T, et al. Population-based metagenomics analysis reveals markers 
for gut microbiome composition and diversity. Science. (2016) 352:565-9. doi: 10.1126/science.aad3369

11. Jandhyala SM, Talukdar R, Subramanyam C, Vuyyuru H, Sasikala M, Reddy DN. Role of the normal gut microbiota. World J Gastroenterol. (2015) 21:8787-803. doi: 10.3748/wjg.v21.i29.8787

12. Maurice CF, Haiser HJ, Turnbaugh PJ. Xenobiotics shape the physiology and gene expression of the active human gut microbiome. Cell. (2013) 152:39-50. doi: 10.1016/j.cell.2012.10.052

13. Sharon G, Garg N, Debelius J, Knight R, Dorrestein PC, Mazmanian SK. Specialized metabolites from the microbiome in health and disease. Cell Metab. (2014) 20:719-30. doi: 10.1016/j.cmet.2014.10.016

14. Vajro P, Paolella G, Fasano A. Microbiota and gut-liver axis: their influences on obesity and obesity-related liver disease. J Pedriatic Gastroenterol Nutr. (2013) 56:461-46. doi: 10.1097/MPG.0b013e318284abb5

15. Boerner BP, Sarvetnick NE. Type 1 diabetes: role of intestinal microbiome in humans and mice. Ann NY Acad Sci. (2011) 1243:103-18. doi: 10.1111/j.1749-6632.2011.06340.x

16. Daïen CI, Pinget GV, Tan JK, Macia L. Detrimental impact of microbiotaaccessible carbohydrate-deprived diet on gut and immune homeostasis: an overview. Front Immunol. (2017) 12:548. doi: 10.3389/fimmu.2017.00548

17. Bonder MJ, Kurilshikov A, Tigchelaar EF, Mujagic Z, Imhann F, Vila AV, et al. The effect of host genetics on the gut microbiome. Nat Genet. (2016) 48:1407-12. doi: 10.1038/ng.3663

18. Ohira H, Tsutsui W, Fujioka Y. Are short chain fatty acids in gut microbiota defensive players for inflammation and atherosclerosis? I Atheroscler Thromb. (2017) 24:660-72. doi: 10.5551/jat.RV17006

19. Wang LL, Guo HH, Huang S, Feng CL, Han YX, Jiang JD. Comprehensive evaluation of SCFA production in the intestinal bacteria regulated by berberine using gas-chromatography combined with polymerase chain reaction. J Chromatogr B Analyt Technol Biomed Life Sci. (2017) 1057:70-80. doi: 10.1016/j.jchromb.2017.05.004

20. Albenberg LG, Wu GD. Diet and the intestinal microbiome: associations, functions, and implications for health and disease. Gastroenterology. (2014) 146:1564-72. doi: 10.1053/j.gastro.2014.01.058

21. Furusawa Y, Obata Y, Fukuda S, Endo TA, Nakato G, Takahashi D, et al. Commensal microbe-derived butyrate induces the differentiation of colonic regulatory T cells. Nature. (2013). 504:446-50. doi: 10.1038/nature12721

22. Kim MH, Kang SG, Park JH, Yanagisawa M, Kim CH. Short-chain fatty acids activate GPR41 and GPR43 on intestinal epithelial cells to promote inflammatory responses in mice. Gastroenterology. (2013) 145:396-406. doi: 10.1053/j.gastro.2013.04.056

23. Heianza Y, Qi L. Gene-diet interaction and precision nutrition in obesity. Int J Mol Sci. (2017) 18:E787. doi: 10.3390/ijms18040787

24. Chen ML, Yi L, Zhang Y, Zhou X, Ran L, Yang J, et al. Resveratrol attenuates Trimethylamine-N-Oxide (TMAO)-induced atherosclerosis by regulating TMAO synthesis and bile acid metabolism via remodeling of the gut microbiota. mBio. (2016) 7:e00210-5. doi: 10.1128/mBio.02210-15

25. Dimitrov D, Thiele I, Ferguson LR. Editorial : the human gutome : nutrigenomics of host-microbiome interactions. Front Genet. (2016) 7:158. doi: 10.3389 /fgene.2016.00158

26. Craig SA. Betaine in human nutrition. Am J Clin Nutr. (2004) 80:539-49. doi: $10.1093 /$ ajcn/80.3.539

27. Levy M, Thaiss CA, Elinav E. Metabolites: messengers between the microbiota and the immune system. Genes Dev. (2016) 30:1589-97. doi: 10.1101/gad.284091.116

28. Collins SM, Surette M, Bercik P. The interplay between the intestinal microbiota and the brain. Nat Rev Microbiol. (2012) 10:735-42. doi: $10.1038 /$ nrmicro2876

29. Heiss CN, Olofsson LE. Gut microbiota-dependent modulation of energy metabolism. J Innate Immun. (2018) 10:163-71. doi: 10.1159/000481519

30. Shenderov BA. Gut indigenous microbiota and epigenetics. Microb Ecol Health Dis. (2012) 23:17195. doi: 10.3402/mehd.v23i0.17195

31. Bonder MJ, Tigchelaar EF, Cai X, Trynka G, Cenit MC, Hrdlickova B, et al. The influence of a short-term gluten-free diet on the human gut microbiome. Genome Med. (2016) 8:45. doi: 10.1186/s13073-016-0295-y

32. Buitrago-Lopez A, Sanderson J, Johnson L, Warnakula S, Wood A, Di Angelantonio E, et al. Chocolate consumption and cardiometabolic disorders: systematic review and meta-analysis. BMJ. (2011) 343:d448. doi: $10.1136 /$ bmj.d4488

33. Burcelin R. The hologenome theory of metabolic diversity. Mol Metab. (2016) 5:771-81. doi: 10.1016/j.molmet.2016.05.016

34. Zilber-Rosenberg I, Rosenberg E. Role of microorganisms in the evolution of animals and plants: the hologenome theory of evolution. FEMS Microbiol Rev. (2008) 32:723-35. doi: 10.1111/j.1574-6976.2008.00123.x

35. Qin Y, Wade PA. Crosstalk between the microbiome and epigenome: messages from bugs. J Biochem. (2018) 163:105-12. doi: 10.1093/jb/mvx080

36. Kumar P, Gogulamudi VR, Peryasamy R, Raghavaraju G, Subramania U, Pandey KN. Inhibition of HDAC enhances STAT acetylation, blocks NF-KappaB, and suppresses the renal inflammation and fibrosis in Nprl haplotype male mice. Am. J. Physiol. Renal Physiol. (2017) 313:F781-95. doi: 10.1152/ajprenal.00166.2017

37. World Health Organisation. Global Report on Diabetes, World Health Organisation (2016)

38. International Diabetes Federation (2017). IDF Diabetes Atlas, 8th Edn. Available online at: http://diabetesatlas.org/resources/2017-atlas.html

39. Ogurtsova K, Da Rocha Fernandes JD, Huang Y, Linnenkamp U, Guariguata L, Cho NH, et al. IDF diabetes atlas: global estimates for the prevalence of diabetes for 2015 and 2040. Diabetes Res Clin Pract. (2017) 128:40-50. doi: 10.1016/j.diabres.2017.03.024

40. Phillips CM. Nutrigenetics and metabolic disease: current status and implications for personalised nutrition. Nutrients. (2013) 5:32-57. doi: 10.3390/nu5010032

41. Paneni F, Costantino S, Cosentino F. Insulin resistance, diabetes, and cardiovascular risk. Curr Atheroscler Rep. (2014) 16:419. doi: 10.1007/s11883-014-0419-z

42. Doros R, Lixandru D, Petcu L, Tudosoiu J, Mitu M, Picu A, et al. Resting metabolic rate in type 2 diabetes-accuracy of predictive equations. Rom Biotechnol Lett. (2016) 22:12033-8.

43. Trayhurn P, Bing C, Wood IS. Adipose tissue and adipokines-energy regulation from the human perspective. J Nutr. (2006) 136:1935S-9S. doi: 10.1093/jn/136.7.1935S

44. Zhang Y, Proenca R, Maffei M, Barone M, Leopold L, Friedman JM. Positional cloning of the mouse obese gene and its human homolog. Nature. (1994) 372:425-32. doi: 10.1038/372425a0

45. World Health Organization. Definition, Diagnosis and Classification of Diabetes Mellitus and Its Complications : Report of a WHO Consultation. Part 1, Diagnosis and Classification of Diabetes Mellitus. Geneva (1999).

46. Guzik TJ, Cosentino F. Epigenetics and immunometabolism in diabetes and aging. Antioxid Redox Signal. (2018) 29:253-74. doi: 10.1089/ars.2017.7299

47. Ionescu-Tîrgovişte C. Treatise on Diabetes Paulescu. Bucharest: Academy (2004).

48. Turer AT, Scherer PE. Adiponectin: mechanistic insights and clinical implications. Diabetologia. (2012) 55:2319-26. doi: 10.1007/s00125-012-2598-x

49. Weisberg SP, Hunter D, Huber R, Lemieux J, Slaymaker S, Vaddi K, et al. CCR2 modulates inflammatory and metabolic effects of high-fat feeding. $J$ Clin Invest. (2006) 116:115-20. doi: 10.1172/JCI24335

50. El Homsi M, Ducroc R, Claustre J, Jourdan G, Gertler A, Estienne M, et al. Leptin modulates the expression of secreted and membrane-associated mucins in colonic epithelial cells by targeting PKC, PI3K, and MAPK pathways. Am J Physiol Gastrointest Liver Physiol. (2007). 293:G365-73. doi: 10.1152/ajpgi.00091.2007

51. Wellen KE, Hotamisligil GS. Inflammation, stress and diabetes. J Clin Invest. (2005) 115:1111-9. doi: 10.1172/JCI25102

52. Ceriello A, Motz E. Is oxidative stress the pathogenic mechanism underlying insulin resistance, diabetes, and cardiovascular disease? Arterioscler Thromb Vasc Biol. (2004) 24:816-23. doi: 10.1161/01.ATV.0000122852.22604.78

53. Kunisaki M, Bursell SE, Clermont AC, Ishii H, Ballas LM, Jirousek MR, et al. Vitamin E prevents diabetes-induced abnormal retinal blood flow via the diacylglycerol-protein kinase C pathway. Am J Physiol. (1995) 269:E239-46. doi: 10.1152/ajpendo.1995.269.2.E239

54. King GL, Brownlee M. The cellular and molecular mechanisms of diabetic complications. Endocrinol Metab Clin North Am. (1996) 25:255-70. doi: 10.1016/S0889-8529(05)70324-8 
55. Jones DP. Radical-free biology of oxidative stress. Am J Physiol Cell Physiol. (2008) 295:C849-68. doi: 10.1152/ajpcell.00283.2008

56. Timofte D, Toarba C, Hogas S, Covic A, Ciobica A, Chirita R, et al. The relevance of oxidative stress status in type 2 diabetes and the chronic consumption of alcohol. Rom Biotechnol Lett. (2016) 21:11246-53.

57. Lazo-de-la-Vega-Monroy ML, Fernandez-Mejia C. Oxidative stress in diabetes mellitus and the role of vitamins with antioxidant actions. In: Morales-Gonzalez JA, editor. Oxidative Stress and Chronic Degenerative Diseases, London: IntechOpen (2013), 209-232. doi: 10.5772/51788

58. Albenberg L, Esipova TV, Judge CP, Bittinger K, Chen J, Laughlin A, et al. Correlation between intraluminal oxygen gradient and radial partitioning of intestinal microbiota. Gastroenterology. (2014) 147:105563.e8. doi: 10.1053/j.gastro.2014.07.020

59. Winter SE, Lopez CA, Bäumler AJ. The dynamics of gut-associated microbial communities during inflammation. EMBO Rep. (2013) 14:319-27. doi: 10.1038/embor.2013.27

60. Lopez CA, Miller BM, Rivera-Chavez F, Velasquez EM, Byndloss MX, Chávez-Arroyo A, et al. Virulence factors enhance citrobacter rodentium expansion through aerobic respiration. Science. (2016) 353:1249-53. doi: $10.1126 /$ science.aag 3042

61. Guinane CM, Cotter P. Role of the gut microbiota in health and chronic gastrointestinal disease: understanding a hidden metabolic organ. Therap Adv Gastroenterol. (2013) 6:295-308. doi: 10.1177/1756283X13482996

62. Bischoff SC, Barbara G, Buurman W, Ockhuizen T, Schulzke JD, Serino $\mathrm{M}$, et al. Intestinal permeability - a new target for disease prevention and therapy. BMC Gastroenterol. (2014) 18:14189. doi: 10.1186/s12876-014-0189-7

63. Tolhurst G, Heffron H, Lam YS, Parker HE, Habib AM, Diakogiannaki E, et al. Short-chain fatty acids stimulate glucagon-like peptide-1 secretion via the G-protein-coupled receptor FFAR2. Diabetes. (2012) 61:364-71. doi: $10.2337 / \mathrm{db} 11-1019$

64. Bäckhed F, Ding H, Wang T, Hooper LV, Koh GY, Nagy A, et al. The gut microbiota as an environmental factor that regulates fat storage. Proc Natl Acad Sci USA. (2004) 101:15718-23. doi: 10.1073/pnas.0407076101

65. Dumas ME, Barton RH, Toye A, Cloarec O, Blancher C, Rothwell A, et al. Metabolic profiling reveals a contribution of gut microbiota to fatty liver phenotype in insulin-resistant mice. Proc Natl Acad Sci USA. (2006) 103:12511-6. doi: 10.1073/pnas.0601056103

66. Hattori M, Taylor TD. The human intestinal microbiome: a new frontier of human biology. DNA Res. (2009) 16:1-12. doi: 10.1093/dnares/dsn033

67. Oldstone MB. Prevention of type I diabetes in nonobese diabetic mice by virus infection. Science. (1988) 239:500-2. doi: 10.1126/science.239.4839.500

68. King C, Sarvetnick N. The incidence of type-1 diabetes in NOD mice is modulated by restricted flora not germ-free conditions. PLoS ONE. (2011) 6:e17049. doi: 10.1371/journal.pone.0017049

69. Brugman S, Klatter FA, Visser JT, Wildeboer-Veloo AC, Harmsen HJ, Rozing J, et al. Antibiotic treatment partially protects against type 1 diabetes in the bio-breeding diabetes-prone rat. Is the gut flora involved in the development of type 1 diabetes? Diabetologia. (2006) 49:2105-8. doi: 10.1007/s00125-006-0334-0

70. Patterson E, Marques TM, O'Sullivan O, Fitzgerald P, Fitzgerald GF, Cotter PD, et al. Streptozotocin-induced type-1-diabetes disease onset in sprague-dawley rats is associated with an altered intestinal microbiota composition and decreased diversity. Microbiology. (2015) 161:182-93. doi: 10.1099/mic.0.082610-0

71. Neu J, Reverte CM, Mackey AD, Liboni K, Tuhacek-Tenace LM, Hatch $\mathrm{M}$, et al. Changes in intestinal morphology and permeability in the biobreeding rat before the onset of type 1 diabetes. J Pediatr Gastroenterol Nutr. (2005) 40:589-95.

72. Watts T, Berti I, Sapone A, Gerarduzzi T, Not T, Zielke R, et al. Role of the intestinal tight junction modulator zonulin in the pathogenesis of type I diabetes in BB diabetic-prone rats. Proc Natl Acad Sci USA. (2005) 102:2916-21. doi: 10.1073/pnas.0500178102

73. Valladares R, Sankar D, Li N, Lai KK, Abdelgeliel AS, Gonzalez CF, et al. Lactobacillus johnsonii N6. 2mitigates the development of type 1 diabetes in BB-DP rats. PLoS ONE. (2010) 5:e10507. doi: 10.1371/journal.pone. 0010507
74. Wen L, Ley RE, Volchkov PY, Stranges PB, Avanesyan L, Stonebraker AC, et al. Innate immunity and intestinal microbiota in the development of type 1 diabetes. Nature. (2008) 455:1109-13. doi: 10.1038/nature07336

75. Lagier J, Armougom F, Million M, Hugon P, Pagnier I, Robert C, et al. Microbial culturomics : paradigm shift in the human gut microbiome study. Clin Microbiol Infect. (2012) 18:1185-93. doi: 10.1111/1469-0691.12023

76. Vaarala O. Gut microbiota and type 1 diabetes. Rev Diabet Stud. (2012) 9:251-9. doi: 10.1900/RDS.2012.9.251

77. Brown CT, Davis-Richardson AG, Giongo A, Gano KA, Crabb DB, Mukherjee N, et al. Gut microbiome metagenomics analysis suggests a functional model for the development of autoimmunity for type 1 diabetes. PLoS ONE. (2011) 6:e25792. doi: 10.1371/journal.pone.0025792

78. Ley RE, Bäckhed F, Turnbaugh P, Lozupone CA, Knight RD, Gordon JI. Obesity alters gut microbial ecology. Proc Natl Acad Sci USA. (2005) 102:11070-5. doi: 10.1073/pnas.0504978102

79. Qin J, Li Y, Cai Z, Li S, Zhu J, Zhang F, et al. A metagenome-wide association study of gut microbiota in type 2 diabetes. Nature. (2012) 490:55-60. doi: $10.1038 /$ nature 11450

80. De Goffau MC, Luopajärvi K, Knip M, Ilonen J, Ruohtula T, Härkönen $\mathrm{T}$, et al. Fecal microbiota composition differs between children with $\beta$-cell autoimmunity and those without. Diabetes. (2013) 62:1238-44. doi: $10.2337 / \mathrm{db} 12-0526$

81. Murri M, Leiva I, Gomez-Zumaquero JM, Tinahones F, Cardona F, Soriguer F, et al. Gut microbiota in children with type 1 diabetes differs from that in healthy children: a case-control study. BMC Med. (2013) 11:46. doi: 10.1186/1741-7015-11-46

82. Kostic $\mathrm{AD}$, Gevers $\mathrm{D}$, Siljander H, Vatanen T, Hyötyläinen T, Hämäläinen $\mathrm{AM}$, et al. The dynamics of the human infant gut microbiome in development and in progression toward type 1 diabetes. Cell Host Microb. (2015) 17:260-73. doi: 10.1016/j.chom.2015.01.001

83. De Groot PF, Belzer C, Aydin Ö, Levin E, Levels JH, Aalvink S, et al. Distinct fecal and oral microbiota composition in human type 1 diabetes, an observational study. PLoS ONE. (2017) 12:e0188475. doi: 10.1371/journal.pone.0188475

84. Larsen N, Vogensen FK, van den Berg FW, Nielsen DS, Andreasen AS, Pedersen BK, et al. Gut microbiota in human adults with type 2 diabetes differs from non-diabetic adults. PLoS ONE. (2010) 5:e9085. doi: 10.1371/journal.pone.0009085

85. Suceveanu AI, Pantea Stoian A, Parepa RI, Voinea C, Hainarosie R, Manuc $\mathrm{D}$, et al. Gut microbiota patterns in obese and type 2 diabetes. (T2D) patients from romanian black sea coast region. Rev Chim. (2018) 69:2260-7.

86. Chelariu M, Grosu M, Gheorghe I, Pircalabioru GG, Picu A, Petcu L, et al. Host metabolic syndrome can disrupt the intestinal microbiota and promote the acquisition of resistance and virulence genes in enterobacteriaceae stains. Rom BiotechnolLett. (2017) 22:12643-50.

87. Fei N, Zhao L. An opportunistic pathogen isolated from the gut of an obese human causes obesity in germfree mice. ISME J. (2013) 7:880-4. doi: 10.1038/ismej.2012.153

88. de La Serre CB, Ellis CL, Lee J, Hartman AL, Rutledge JC, Raybould HE. Propensity to high-fat diet-induced obesity in rats is associated with changes in the gut microbiota and gut inflammation. Am J Physiol Gastrointest Liver Physiol. (2010) 299:G440-8. doi: 10.1152/ajpgi.00098.2010

89. Festi D, Schiumerini R, Eusebi LH, Marasco G, Taddia M, Colecchia A. Gut microbiota and metabolic syndrome.World J Gastroenterol. (2014) 20:16079-94. doi: 10.3748/wjg.v20.i43.16079

90. Amar J, Chabo C, Waget A, Klopp P, Vachoux C, BermúdezHumarán LG, et al. Intestinal mucosal adherence and translocation of commensal bacteria at the early onset of type 2 diabetes: molecular mechanisms and probiotic treatment. EMBO Mol Med. (2011) 3:559-72. doi: $10.1002 / \mathrm{emmm} .201100159$

91. Caricilli A, Saad M. The role of gut microbiota on insulin resistance. Nutrients. (2013) 5:829-51. doi: 10.3390/nu5030829

92. König J, Wells J, Cani PD, García-Ródenas CL, MacDonald T, Mercenier A, et al. Human intestinal barrier function in health and disease. Clin Transl Gastroenterol. (2016) 7:e196. doi: 10.1038/ctg.2016.54

93. Furet JP, Kong LC, Tap J, Poitou C, Basdevant A, Bouillot JL, et al. Differential adaptation of human gut microbiota to bariatric surgery-induced weight loss: 
links with metabolic and low-grade inflammation markers. Diabetes. (2010) 59:3049-57. doi: 10.2337/db10-0253

94. Kootte RS, Levin E, Salojärvi J, Smits LP, Hartstra AV, Udayappan SD, et al. Improvement of insulin sensitivity after lean donor feces in metabolic syndrome is driven by baseline intestinal microbiota composition. Cell Metab. (2017) 26:611-9.e6. doi: 10.1016/j.cmet.2017.09.008

95. Singh RK, Chang HW, Yan D, Lee KM, Ucmak D, Wong K, et al. Influence of diet on the gut microbiome and implications for human health. J Transl Med. (2017) 15:73. doi: 10.1186/s12967-017-1175-y

96. Sanz Y. Effects of a gluten free diet on gut microbiota and immune function in healthy adult humans. Gut Microbes. (2010) 1:135-7. doi: 10.4161/gmic.1.3.11868

97. de Vrese M, Schrezenmeir J. Probiotics, prebiotics, and synbiotics. Adv Biochem Eng Biotechnol. (2008) 111:1-66. doi: 10.1007/10_2008_097

98. Cotillard A, Kennedy SP, Kong LC, Prifti E, Pons N, Le Chatelier E, et al. Dietary intervention impact on gut microbial gene richness. Nature. (2013) 500:585-8. doi: 10.1038/nature12480

99. Carvalho-Wells AL, Helmolz K, Nodet C, Molzer C, Leonard C, McKevith B, et al. Determination of the in vivo prebiotic potential of a maizebased whole grain breakfast cereal: a human feeding study. Br J Nutr. (2010) 104:1353-6. doi: $10.1017 /$ S0007114510002084

100. Costabile A, Klinder A, Fava F, Napolitano A, Fogliano V, Leonard C, et al. Whole-grain wheat breakfast cereal has a prebiotic effect on the human gut microbiota: a double-blind, placebo-controlled, crossover study. Br J Nutr. (2008) 99:110-20. doi: 10.1017/S0007114507793923

101. Wu GD, Compher C, Chen EZ, Smith SA, Shah RD, Bittinger K, et al. Comparative metabolomics in vegans and omnivores reveal constraints on diet-dependent Gut microbiota metabolite production. Gut. (2016) 65:6372. doi: 10.1136/gutjnl-2014-308209

102. Lopez-Legarrea P, Fuller NR, Zulet MA, Martinez JA, Caterson ID. The influence of mediterranean, carbohydrate and high protein diets on gut microbiota composition in the treatment of obesity and associated inflammatory state. Asia Pac J Clin Nutr. (2014) 23:360-8. doi: 10.6133/apjen.2014.23.3.16

103. Villegas R, Shu XO, Gao YT, Yang G, Elasy T, Li H, et al. Vegetable but not fruit consumption reduces the risk of type 2 diabetes in Chinese women. $J$ Nutr. (2008) 138:574-80. doi: 10.1093/jn/138.3.574

104. Hentges DJ, Maier BR, Burton GC, Flynn MA, Tsutakawa RK. Effect of a high-beef diet on the fecal bacterial flora of humans. Cancer Res. (1977) 37:568-71.

105. David LA, Maurice CF, Carmody RN, Gootenberg DB, Button JE, Wolfe $\mathrm{BE}$, et al. Diet rapidly and reproducibly alters the human gut microbiome. Nature. (2014) 505:559-63. doi: 10.1038/nature12820

106. Lecomte V, Kaakoush NO, Maloney CA, Raipuria M, Huinao KD, Mitchell $\mathrm{HM}$, et al. Changes in gut microbiota in rats fed a high fat diet correlate with obesity-associated metabolic parameters. PLoS ONE. (2015) 10:e0126931. doi: 10.1371/journal.pone.0126931

107. Devkota S, Wang Y, Musch MW, Leone V, Fehlner-Peach H, Nadimpalli A, et al. Dietary-fat-induced taurocholic acid promotes pathobiont expansion and colitis in Il10-/- mice. Nature. (2013) 487:104-8. doi: 10.1038/nature11225

108. Prieto I, Hidalgo M, Segarra AB, Martínez-Rodríguez AM, Cobo A, Ramírez $\mathrm{M}$, et al. Influence of a diet enriched with virgin olive oil or butter on mouse gut microbiota and its correlation to physiological and biochemical parameters related to metabolic syndrome. PLoS ONE. (2018) 13:e0190368. doi: 10.1371/journal.pone. 0190368

109. Wu GD, Chen J, Hoffmann C, Bittinger K, Chen YY, Keilbaugh SA, et al. Linking long-term dietary patterns with gut microbial enterotypes. Science. (2011) 334:105-8. doi: 10.1126/science.1208344

110. Serino M, Luche E, Gres S, Baylac A, Bergé M, Cenac C, et al. Metabolic adaptation to a high-fat diet is associated with a change in the gut microbiota. Gut. (2012) 61:543-53. doi: 10.1136/gutjnl-2011-301012

111. Caesar R, Tremaroli V, Kovatcheva-Datchary P, Cani PD, Bäckhed F. Crosstalk between gut microbiota and dietary lipids aggravates WAT inflammation through TLR signaling. Cell Metab. (2015) 22:658-68. doi: 10.1016/j.cmet.2015.07.026

112. Bai Y, Sun Q. Macrophage recruitment in obese adipose tissue. Obes Rev. (2015) 16:127-36. doi: 10.1111/obr.12242
113. Jin C, Flavell RA. Innate sensors of pathogen and stress: linking inflammation to obesity. J Allergy Clin Immunol. (2013) 132:287-94. doi: 10.1016/j.jaci.2013.06.022

114. Shi H, Kokoeva MV, Inouye K, Tzameli I, Yin H, Flier JS. TLR4 links innate immunity and fatty acid-induced insulin resistance. J Clin Invest. (2006) 116:3015-25. doi: 10.1172/JCI28898

115. Ivanov II, Atarashi K, Manel N, Brodie EL, Shima T, Karaoz U, et al. Induction of intestinal Th17 Cells by segmented filamentous bacteria. Cell. (2009) 139:485-98. doi: 10.1016/j.cell.2009.09.033

116. Ramos-Romero S, Hereu M, Atienza L, Casas J, Jáuregui O, Amézqueta S, et al. Mechanistically different effects of fat and sugar on insulin resistance, hypertension and gut microbiota in rats. Am J Physiol Endocrinol Metab. (2018) 314:E552-63. doi: 10.1152/ajpendo.00323.2017

117. Levine ME, Suarez JA, Brandhorst S, Balasubramanian P, Cheng CW, Madia F, et al. Low protein intake is associated with a major reduction in IGF-1, cancer, and overall mortality in the 65 and younger but not older population. Cell Metab. (2014) 19:407-17. doi: 10.1016/j.cmet.2014.02.006

118. Bäckhed F, Manchester JK, Semenkovich CF, Gordon JI. Mechanisms underlying the resistance to diet-induced obesity in germ-free mice. Proc Natl Acad Sci USA. (2007) 104:979-84. doi: 10.1073/pnas.0605374104

119. Seidell JC. Dietary fat and obesity: an epidemiologic perspective. Am J Clin Nutr. (1998) 67:546S-50S. doi: 10.1093/ajcn/67.3.546S

120. Bărbulescu ID, Marinescu SI, Begea M, Teodorescu RI. Reducing sugar in food as an option for lowering the risk of diabetes. Rom Biotechnol Lett. (2016) 21:11263-71.

121. Eid N, Enani S, Walton G, Corona G, Costabile A, Gibson G, et al. The impact of date palm fruits and their component polyphenols, on gut microbial ecology, bacterial metabolites and colon cancer cell proliferation. J Nutr Sci. (2014) 3:e46. doi: 10.1017/jns.2014.16

122. Francavilla R, Calasso M, Calace L, Siragusa S, Ndagijimana M, Vernocchi $P$, et al. Effect of lactose on gut microbiota and metabolome of infants with Cow's milk allergy. Pediatr Allergy Immunol. (2012) 23:420-7. doi: 10.1111/j.1399-3038.2012.01286.x

123. Nseir W, Nassar F, Assy N. Soft drinks consumption and nonalcoholic fatty liver disease. World $J$ Gastroenterol. (2010) 16:2579-88. doi: 10.3748/wjg.v16.i21.2579

124. Amin TT, Al-Sultan AI, Ali A. Overweight and obesity and their association with dietary habits, and sociodemographic characteristics among male primary school children in Al-Hassa, kingdom of Saudi Arabia. Indian J Community Med. (2008) 33:172-81. doi: 10.4103/0970-0218.42058

125. Ludwig DS, Peterson KE, Gortmaker SL. Relation between consumption of sugar-sweetened drinks and childhood obesity: a prospective, observational analysis. Lancet. (2001) 357:505-8. doi: 10.1016/S0140-6736(00)04041-1

126. Suez J, Korem T, Zeevi D, Zilberman-Schapira G, Thaiss CA, Maza O, et al. Artificial sweeteners induce glucose intolerance by altering the gut microbiota. Nature. (2014) 514:181-6. doi: 10.1038/nature13793

127. Machiels K, Joossens M, Sabino J, De Preter V, Arijs I, Eeckhaut V, et al. A decrease of the butyrate-producing species Roseburia hominis and Faecalibacterium prausnitzii defines dysbiosis in patients with ulcerative colitis. Gut. (2014) 63:1275-83. doi: 10.1136/gutjnl-2013-304833

128. Falony G, Joossens M, Vieira-Silva S, Wang J, Darzi Y, Faust K, et al. Population-level analysis of gut microbiome variation. Science. (2016) 6285:560-4. doi: 10.1126/science.aad3503

129. Kim Y, Keogh JB, Clifton PM. Polyphenols and glycemic control. Nutrients. (2016) 8:17. doi: 10.3390/nu8010017

130. Queipo-Ortuno MI, Boto-Ordonez M, Murri M, Gomez-Zumaquero JM, Clemente-Postigo M, Estruch R, et al. Influence of red wine polyphenols and ethanol on the gut microbiota ecology and biochemical biomarkers. Am J Clin Nutr. (2012) 95:1323-34. doi: 10.3945/ajcn.111.027847

131. Hooper L, Kay C, Abdelhamid A, Kroon PA, Cohn JS, Rimm EB, et al. Effects of chocolate, cocoa, and flavan-3-ols on cardiovascular health: a systematic review and meta-analysis of randomized trials. Am J Clin Nutr. (2012) 95:740-51. doi: 10.3945/ajcn.111.023457

132. Almoosawi S, Tsang C, Ostertag LM, Fyfe L, Dujaili EA. Differential effect of polyphenol-rich dark chocolate on biomarkers of glucose metabolism and cardiovascular risk factors in healthy, overweight and obese subjects: a randomized clinical trial. Food Funct. (2012) 3:1035-43. doi: $10.1039 / \mathrm{c} 2$ fo $30060 \mathrm{e}$ 
133. Davison K, Coates AM, Buckley JD, Howe PR. Effect of Cocoa Flavanols and exercise on cardiometabolic risk factors in overweight and obese subjects. Int J Obes. (2008) 32:1289-96. doi: 10.1038/ijo.2008.66

134. Rostami A, Khalili M, Haghighat N, Eghtesadi S, Shidfar F, Heidari I, et al. High-cocoa polyphenol-rich chocolate improves blood pressure in patients with diabetes and hypertension. ARYA Atheroscler. (2015) 11:21-9.

135. Khan A, Safdar M, Ali Khan MM, Khattak KN, Anderson RA. Cinnamon improves glucose and lipids of people with type 2 diabetes. Diabetes Care. (2003) 26:3215-8. doi: 10.2337/diacare.26.12.3215

136. Mang B, Wolters M, Schmitt B, Kelb K, Lichtinghagen R, Stichtenoth DO, et al. Effects of a cinnamon extract on plasma glucose, hba, and serum lipids in diabetes mellitus type 2. Eur J Clin Invest. (2006) 36:340-4. doi: 10.1111/j.1365-2362.2006.01629.x

137. Blevins SM, LeyvaMJ, Brown J, Wright J, Scofield RH, Aston CE. Effect of cinnamon on glucose and lipid levels in non insulin-dependent type 2 diabetes. Diabetes Care. (2007). 30:2236-7. doi: 10.2337/dc07-0098

138. Vanschoonbeek K, Thomassen BJ, Senden JM, Wodzig WK, van Loon LJ. Cinnamon supplementation does not improve glycemic control in postmenopausal type 2 diabetes patients. J Nutr. (2006) 136:977-80. doi: $10.1093 /$ jn $/ 136.4 .977$

139. Tang M, Larson-Meyer DE, Liebman M. Effect of cinnamon and turmeric on urinary oxalate excretion, plasma lipids, and plasma glucose in healthy subjects. Am J Clin Nutr. (2008) 87:1262-7. doi: 10.1093/ajcn/87.5.1262

140. Altschuler JA, Casella SJ, MacKenzie TA, Curtis KM. The effect of cinnamon on A1C among adolescents with type 1 diabetes. Diabetes Care. (2007) 30:813-6. doi: 10.2337/dc06-1871

141. Akilen R, Tsiami A, Devendra D, Robinson N. Glycated haemoglobin and blood pressure-lowering effect of cinnamon in multi-ethnic type 2 diabetic patients in the UK: a randomized, placebo-controlled, double-blind clinical trial. Diabet Med. (2010) 27:1159-67. doi: 10.1111/j.1464-5491.2010.03079.x

142. Wainstein J, Ganz T, Boaz M, Bar Dayan Y, Dolev E, Kerem Z, et al. Olive leaf extract as a hypoglycemic agent in both human diabetic subjects and in rats. J Med Food. (2012) 15:605-610. doi: 10.1089/jmf.2011.0243

143. Timmers S, Konings E, Bilet L, Houtkooper RH, van de Weijer T, Goossens GH, et al. Calorie restriction-like effects of 30 days of resveratrol supplementation on energy metabolism and metabolic profile in obese humans. Cell Metab. (2011) 14:612-22. doi: 10.1016/j.cmet.2011.10.002

144. Pérez-Jiménez J, Neveu V, Vos F, Scalbert A. Identification of the 100 richest dietary sources of polyphenols: an application of the phenol-explorer database. Eur J Clin Nutr. (2010) 64:S112-20. doi: 10.1038/ejcn.2010.221

145. Ye EQ, Chacko SA, Chou EL, Kugizaki M, Liu S. Greater whole-grain intake is associated with lower risk of type 2 diabetes, cardiovascular disease, and weight gain. J Nutr. (2012) 142:1304-13. doi: 10.3945/jn.111.155325

146. Kovatcheva-Datchary P, Nilsson A, Akrami R, Lee YS, De Vadder F, Arora T, et al. Dietary fiber-induced improvement in glucose metabolism is associated with increased abundance of prevotella. Cell Metab. (2015) 22:971-82. doi: 10.1016/j.cmet.2015.10.001

147. Estruch R. Anti-inflammatory effects of the mediterranean diet: the experience of the predimed study. Proc Nutr Soc. (2010) 69:333-40. doi: 10.1017/S0029665110001539

148. Salas-Salvado J, Bullo M, Estruch R, Ros E, Covas MI, Ibarrola-Jurado $\mathrm{N}$, et al. Prevention of diabetes with mediterranean diets: a subgroup analysis of a randomized trial. Ann Int Med. (2014) 160:1-10. doi: 10.7326/ M13-1725

149. De Bock M, Derraik JG, Brennan CM, Biggs JB, Morgan PE, Hodgkinson SC, et al. Olive (Olea Europaea l.) leaf polyphenols improve insulin sensitivity in middle-aged overweight men: a randomized, placebo-controlled, crossover trial. PLoS ONE. (2013) 8:e57622. doi: 10.1371/journal.pone.0057622

150. Shiomi Y, Nishiumi S, Ooi M, Hatano N, Shinohara M, Yoshie T, et al. GCMS-based metabolomic study in mice with colitis induced by dextran sulfate sodium. Inflamm Bowel Dis. (2011) 17:2261-74. doi: 10.1002/ibd.21616

151. Russell WR, Gratz SW, Duncan SH, Holtrop G, Ince J, Scobbie L, et al. Highprotein, reduced-carbohydrate weight-loss diets promote metabolite profiles likely to be detrimental to colonic health. Am J Clin Nutr. (2011) 93:1062-72. doi: 10.3945/ajcn.110.002188

152. De Filippis F, Pellegrini N, Vannini L, Jeffery IB, La Storia A, Laghi L, et al. High-Level Adherence to a Mediterranean Diet Beneficially Impacts the Gut Microbiota and Associated Metabolome. Gut. (2016) 65:1812-21. doi: 10.1136/gutjnl-2015-309957

153. Stamler J, Daviglus ML, Garside DB, Dyer AR, Greenland P, Neaton JD. Relationship of baseline serum cholesterol levels in 3 large cohorts of younger men to long-term coronary, cardiovascular, and all-cause mortality and to longevity. JAMA. (2000) 284:311-8. doi: 10.1001/jama.284.3.311

154. Drasar BS, Crowther JS, Goddard P, Hawksworth G, Hill MJ, Peach S, et al. The relation between diet and the gut microflora in man. Proc Nutr Soc. (2007) 32:49-52. doi: 10.1079/PNS19730014

155. Fava F, Gitau R, Griffin BA, Gibson GR, Tuohy KM, Lovegrove JA. The type and quantity of dietary fat and carbohydrate alter faecal microbiome and short-chain fatty acid excretion in a metabolic syndrome 'at-risk' population. Int J Obes. (2013) 37:216-23. doi: 10.1038/ijo.2012.33

156. Ferguson LR, De Caterina R, Görman U, Allayee H, Kohlmeier M, Prasad C, et al. Guide and position of the international society of nutrigenetics/nutrigenomics on personalised nutrition: part 1 - fields of precision nutrition. J Nutrigenet Nutrigenomics. (2016) 9:12-27. doi: $10.1159 / 000445350$

157. Kaati G, Bygren LO, Edvinsson S. Cardiovascular and diabetes mortality determined by nutrition during parents' and grandparents' slow growth period. Eur J Hum Genet. (2002) 10:682-8. doi: 10.1038/sj.ejhg.5200859

158. Niculescu MD. Epigenetic transgenerational inheritance: should obesityprevention policies be reconsidered? Synesis. (2011) 2:G18-26.

159. Thorsell A, Nätt D. Maternal stress and diet may influence affective behavior and stress-response in offspring via epigenetic regulation of central peptidergic function. Environ Epigenet. (2016) 2:dvw012. doi: 10.1093/eep/dvw012

160. Parlee SD, MacDougald OA. Maternal nutrition and risk of obesity in offspring: the trojan horse of developmental plasticity. Biochim Biophys Acta. (2014) 1842:495-506. doi: 10.1016/j.bbadis.2013.07.007

161. Ross MG, Desai M. Developmental programming of offspring obesity, adipogenesis, and appetite. Clin Obstet Gynecol. (2013) 56:529-36. doi: 10.1097/GRF.0b013e318299c39d

162. Soubry A, Schildkraut JM, Murtha A, Wang F, Huang Z, Bernal A, et al. Paternal obesity is associated with IGF2hypomethylation in newborns: results from a newborn epigenetics. Study (NEST) cohort. BMC Med. (2013) 11:29. doi: 10.1186/1741-7015-11-29

163. Ulrey CL, Liu L, Andrews LG, Tollefsbol TO. The impact of metabolism on DNA methylation. Hum Mol Genet. (2005) 14:R139-47. doi: $10.1093 / \mathrm{hmg} / \mathrm{ddi} 100$

164. Healey GR, Murphy R, Brough L, Butts CA, Coad J. Interindividual variability in gut microbiota and host response to dietary interventions. Nutr Rev. (2017) 75:1059-80. doi: 10.1093/nutrit/nux062

165. Matei B, Salzat J, Diguta CF, Cornea CP, Luta G, Utoiu ER, et al. Lactic acid bacteria strains isolated from kombucha with potential probiotic effect. Rom Biotechnol Lett. (2018) 23:13592-8. doi: 10.26327/RBL2017.133

166. Goanta CM, Cirpaciu D, Tusaliu M, Georgescu M, Ditu LM, Budu VA, et al. Probiotics as a therapeutic option to reduce the duration of upper respiratory tract infections in children. Rom Biotechnol Lett. (2017) 22:12329-33.

167. Mizielinska M, Lopusiewicz L. Encapsulation and evaluation of probiotic bacteria survival in simulated gastrointestinal conditions. Rom Biotechnol Lett. (2018) 23:13690-6.

168. Muresan A, Sarbu I, Pelinescu D, Ionescu R, Csutak O, Stoica I, et al. In vitro selection of some lactic acid bacteria strains with probiotic potential. Rom Biotechnol Lett. (2018) 23:13327-39.

169. Zamfir M, Stefan IR, Grosu-Tudor SS. Influence of growth medium composition on the bacteriocin activity of some lactic acid bacteria. Rom Biotechnol Lett. (2016) 22:12126-35.

170. Yoo JY, Kim SS. Probiotics and prebiotics: present status and future perspectives on metabolic disorders. Nutrients. (2016) 8:173. doi: 10.3390/nu8030173

171. Matsuzaki T, Takagi A, Ikemura H, Matsuguchi T, Yokokura T. Intestinal microflora: probiotics and autoimmunity. J Nutr. (2007) 137:798S-802S. doi: 10.1093/jn/137.3.798S

172. Matsuzaki T, Yamazaki R, Hashimoto S, Yokokura T. Antidiabetic effect of an oral administration of Lactobacillus Casei in a Non-Insulin Dependent Diabetes Mellitus (NIDDM) model using KK-Ay mice. Endocr J. (1997) 44:357-65. doi: 10.1507/endocrj.44.357 
173. Tabuchi M, Ozaki M, Tamura A, Yamada N, Ishida T, Hosoda M, et al. Antidiabetic effect of lactobacillus GG in streptozotocin-induced diabetic rats. Biosci Biotechnol Biochem. (2003) 67:1421-4. doi: 10.1271/bbb. 67.1421

174. Yadav H, Jain S, Sinha PR. Antidiabetic effect of probiotic dahi containing Lactobacillus acidophilus and Lactobacillus casei in high fructose fed rats. Nutrition. (2007) 23:62-8. doi: 10.1016/j.nut.2006.09.002

175. Yadav H, Jain S, Sinha PR. Oral administration of dahi containing probiotic Lactobacillus acidophilus and Lactobacillus casei delayed the progression of streptozotocin- induced diabetes in rats. J Dairy Res. (2008) 75:189-95. doi: 10.1017/S0022029908003129

176. Al-Salami H, Butt G, Tucker I, Skrbic R, Mikov M, Golocorbin-Kon S. Probiotic pre-treatment reduces gliclazide permeation (ex vivo) in healthy rats but increases it in diabetic rats to the level seen in untreated healthy rats. Arch Drug Inf. (2008) 1:35-41. doi: 10.1111/j.1753-5174.2008. 00006.x

177. Panwar H, Rashmi HM, Batish VK, Grover S. Probiotics as potential biotherapeutics in the management of type 2 diabetes - prospects and perspectives. Diabetes Metab Res Rev. (2013) 29:103-12. doi: 10.1002/dmrr.2376

178. Ma X, Hua J, Li Z. Probiotics improve high fat diet-induced hepatic steatosis and insulin resistance by increasing hepatic NKT cells. J Hepatol. (2008) 49:821-30. doi: 10.1016/j.jhep.2008.05.025

179. Andersson U, Bränning C, Ahrné S, Molin G, Alenfall J, Onning G, et al. Probiotics lower plasma glucose in the high-fat fed C57BL/6 J mouse. Benef Microbes. (2010) 12:189-96. doi: 10.3920/BM2009.0036

180. Lu YC, Yin LT, Chang WT, Huang JS. Effect of Lactobacillus reuteri GMNL263 treatment on renal fibrosis in diabetic rats. J Biosci Bioeng. (2010) 110:709-15. doi: 10.1016/j.jbiosc.2010.07.006

181. Manirarora JN, Parnell SA, Hu YH, Kosiewich MM, Alard P. NOD dendritic cells stimulated with Lactobacilli preferentially produce IL-10 versus IL-12 and decrease diabetes incidence. Clin Dev Immunol. (2011) 2011:630187. doi: 10.1155/2011/630187

182. Lee E, Jung SR, Lee SY, Lee NK, Paik HD, Lim SI. Lactobacillus plantarum strain Ln4 attenuates diet-induced obesity, insulin resistance, and changes in hepatic MRNA levels associated with glucose and lipid metabolism. Nutrients. (2018) 10:643. doi: 10.3390/nu10050643

183. Rossi M, Amaretti A, Raimondi S. Folate production by probiotic bacteria. Nutrients. (2011) 3:118-34. doi: 10.3390/nu3010118

184. Ejtahed HS, Mohtadi-Nia J, Homayouni-Rad A, Niafar M, AsghariJafarabadi M, Mofid V. Effect of probiotic yogurt containing Lactobacillus acidophilus and Bifidobacterium lactis on lipid profile in individuals with type 2 mellitus. J Dairy Sci. (2011) 94:3288-94. doi: 10.3168/jds.2010-4128

185. Ejtahed HS, Mohtadi-Nia J, Homayouni-Rad A, Niafar M, AsghariJafarabadi M, Mofid V. Probiotic yogurt improves antioxidant status in type 2 diabetic patients. Nutrition. (2012) 28:539-43. doi: 10.1016/j.nut.2011.08.013

186. Tong X, Xu J, Lian F, Yu X, Zhao Y, Xu L, et al. Structural alteration of gut microbiota during the amelioration of human type 2 diabetes with hyperlipidemia by metformin and a traditional chinese herbal formula: a multicenter, randomized, open label clinical trial. MBio. (2018) 9:e02392117. doi: 10.1128/mBio.02392-17

187. Luoto R, Laitinen $\mathrm{K}$, Nermes $\mathrm{M}$, Isolauri E. Impact of maternal probiotic-supplemented dietary counseling during pregnancy on colostrum adiponectin concentration: a prospective, randomized, placebo-controlled study. Early Hum Dev. (2012) 88:339-44. doi: 10.1016/j.earlhumdev.2011.09.006

188. Kijmanawat A, Panburana P, Reutrakul S, Tangshewinsirikul C. The effects of probiotic supplements on insulin resistance in gestational diabetes mellitus: a double-blind randomized controlled trial. J Diabetes Investig. (2019) 10:16370. doi: $10.1111 /$ jdi. 12863

189. Raygan F, Rezavandi Z, Bahmani F, Ostadmohammadi V, Mansournia MA, Tajabadi-Ebrahimi M, et al. The efects of probiotic supplementation on metabolic status in type 2 diabetic patients with coronary heart disease.
Diabetol Metab Syndr. (2018) 10:51. doi: 10.1186/s13098-018-0353-2

190. Sabico S, Al-Mashharawi A, Al-Daghri NM, Wani K, Amer OE, Hussain DS, et al. Effects of a 6-month multi-strain probiotics supplementation in endotoxemic, inflammatory and cardiometabolic status of T2DM patients: a randomized, double-blind, placebo-controlled trial. Clin Nutr. (2018) 18:31351-7. doi: 10.1016/j.clnu.2018.08.009

191. Zugravu CA, Baciu A, Patrascu D, Tarcea M, Stoian A. Depression and diabetes: are there any consequences on self-care? Eur J Public Health. (2012) 22:272.

192. Raygan F, Ostadmohammadi V, Bahmani F, Asemi Z. The effects of vitamin $\mathrm{D}$ and probiotic co-supplementation on mental health parameters and metabolic status in type 2 diabetic patients with coronary heart disease: a randomized, double-blind, placebo-controlled trial. Prog Neuropsychopharmacol Biol Psychiatry. (2018) 84:50-5. doi: 10.1016/j.pnpbp.2018.02.007

193. Andreasen AS, Larsen N, Pedersen-Skovsgaard T, Berg RM, Møller K, Svendsen KD, et al. Effects of Lactobacillus acidophilus NCFM on insulin sensitivity and the systemic inflammatory response in human subjects. $\mathrm{Br}$ J Nutr. (2010) 10412:1831-8. doi: 10.1017/S0007114510002874

194. Kobyliak N, Falalyeyeva T, Mykhalchyshyn G, Kyriienko D, Komissarenko I. Effect of alive probiotic on insulin resistance in type 2 diabetes patients: randomized clinical trial. Diabetes Metab Syndr. (2018) 12:617-24. doi: 10.1016/j.dsx.2018.04.015

195. Kim M, Shin HK. The water-soluble extract of chicory influences serum and liver lipid concentrations, cecal short-chain fatty acid concentrations and fecal lipid excretion in rats. J Nutr. (1998) 128:1731-6. doi: $10.1093 /$ jn/128.10.1731

196. Gibson GR, Roberfroid M. Dietary modulation of the human colonic microbiota: introducing the concept of prebiotics. J Nutr. (1995) 125:140112. doi: 10.1093/jn/125.6.1401

197. Causey JL, Feirtag JM, Gallaher DD, Tungland BC, Slavin JL. Effects of dietary inulin on serum lipids, blood glucose and the gastrointestinal, environment in hypercholesterolemic men. Nutr Res. (2000) 20:191-201. doi: 10.1016/S0271-5317(99)00152-9

198. Brighenti F, Casiraghi MC, Canzi E, Ferrari A. Effect of consumption of a ready-to-eat breakfast cereal containing inulin on the intestinal milieu and blood lipids in healthy male volunteers. Eur J Clin Nutr. (1999) 53:726-33. doi: 10.1038/sj.ejcn.1600841

199. Dikeman CL, Murphy MR, Fahey GC Jr. Dietary fibers affect viscosity of solutions and simulated human gastric and small intestinal digesta. J Nutr. (2006) 136:913-9. doi: 10.1093/jn/136.4.913

200. Gibson GR, Probert HM, Loo JV, Rastall RA, Roberfroid MB. Dietary modulation of the human colonic microbiota: updating the concept of prebiotics. Nutr Res Rev. (2004) 17:259-75. doi: 10.1079/NRR200479

201. Hald S, Schioldan AG, Moore ME, Dige A, Lærke HN, Agnholt J, et al. Effects of arabinoxylan and resistant starch on intestinal microbiota and short-chain fatty acids in subjects with metabolic syndrome: a randomised crossover study. PLoS ONE. (2016) 11:e0159223. doi: 10.1371/journal.pone.0159223

202. Moroti C, Souza Magri LF, de Rezende Costa M, Cavallini DC, Sivieri $\mathrm{K}$. Effect of the consumption of a new symbiotic shake on glycemia and cholesterol levels in elderly people with type 2 diabetes mellitus. Lipids Health Dis. (2012) 11:29. doi: 10.1186/1476-511X-11-29

Conflict of Interest Statement: The authors declare that the research was conducted in the absence of any commercial or financial relationships that could be construed as a potential conflict of interest.

Copyright (c) 2019 Lazar, Ditu, Pircalabioru, Picu, Petcu, Cucu and Chifiriuc. This is an open-access article distributed under the terms of the Creative Commons Attribution License (CC BY). The use, distribution or reproduction in other forums is permitted, provided the original author(s) and the copyright owner(s) are credited and that the original publication in this journal is cited, in accordance with accepted academic practice. No use, distribution or reproduction is permitted which does not comply with these terms. 